1 Axin proteolysis by Iduna is required for the regulation of stem cell proliferation

\title{
and intestinal homeostasis in Drosophila
}

Yetis Gultekin ${ }^{1}$ and Hermann Steller ${ }^{1 *}$

4

$5{ }^{1}$ Strang Laboratory of Apoptosis and Cancer Biology, The Rockefeller University, 1230

6 York Avenue, New York, NY 10065, USA.

11 E-mail: steller@rockefeller.edu. Strang Laboratory of Apoptosis and Cancer Biology,

12 The Rockefeller University, 1230 York Avenue, New York, NY 10065, USA. Tel: (212)

$13 \quad 327-7075$.

14

15 Running Title: Iduna regulates stem cell proliferation and intestinal homeostasis

17 Keywords: wingless, Axin, ADP-ribosylation, protein degradation, ubiquitin E3 ligase, 18 stem cells. 


\section{Abstract}

22 The self-renewal of intestinal stem cell is controlled by Wingless/Wnt- $\beta$ catenin signaling

23 both in Drosophila and mammals. Since Axin is a rate-limiting factor in Wingless

24 signaling its regulation is essential. Iduna is an evolutionarily conserved ubiquitin E3

25 ligase that has been identified as a critical regulator for degradation of ADP-ribosylated

26 Axin and thus of Wnt/ $\beta$-catenin signaling. However, its physiological significance

27 remains to be demonstrated. Here, we generated loss-of-function mutants of Iduna to

28 investigate its physiological role in Drosophila. Genetic depletion of Iduna causes the

29 accumulation of both Tankyrase and Axin. Increase of Axin protein in enterocytes non-

30 autonomously enhanced stem cell divisions in the Drosophila midgut. Enterocytes

31 secreted Unpaired and thereby stimulated the activity of the JAK-STAT pathway in

32 intestinal stem cells. A decrease in Axin gene expression suppressed both the over-

33 proliferation of stem cells and restored their numbers to normal levels in Iduna mutants.

34 These findings suggest that Iduna-mediated regulation of Axin proteolysis is essential to

35 maintain tissue homeostasis in the Drosophila midgut. 


\section{Introduction}

42 The evolutionarily conserved Wnt/ $\beta$-catenin signaling pathway is a main regulator of

43 animal development. It controls proliferation, differentiation and regeneration of adult

44 tissues (Herr et al., 2012; Nusse and Clevers, 2017). The Wingless pathway is also

45 involved in adult tissue self-renewal in Drosophila (Lin et al., 2008). Genetic depletion of

46 proteins in the Wingless pathway, such as Tcf, arr, dsh and pygo, leads to inhibition of

47 Wingless signaling activation which in turn causes over-proliferation of stem cells in the

48 Drosophila midgut (Kramp et al., 2002; Wang et al., 2016a and 2016b; Tian et al.,

49 2016). However, inactivation of Wnt signaling in the small intestine of mice decreases

50 the proliferative potential of stem cells (Fevr et al., 2007; Korinek et al., 1998). On the

51 other hand, mutations resulting in the over-activation of the $\mathrm{Wnt} / \beta$-catenin pathway

52 promote tumorigenesis (Clevers and Russe, 2012; Andreu et al., 2005; Korinek et al.,

531997 and 1998; Morin et al., 1997). For instance, mutations on adenomatous polyposis

54 coli (APC) gene cause a hereditary colorectal cancer syndrome called familial

55 adenomatous polyposis (Kinzler et al., 1991; Nishisho et al., 1991). Axin loss-of-function

56 mutations are found in hepatocellular carcinomas, while oncogenic $\beta$-catenin mutations

57 are described in colon cancer and melanoma (Rubinfeld et al., 1997). Consequently,

58 intense efforts have been made to target this pathway for therapeutic purposes (Clevers

59 and Russe, 2012).

60 A key feature of the Wnt/ $\beta$-catenin pathway is the regulated proteolysis of the

61 downstream effector $\beta$-catenin by the $\beta$-catenin degradation complex. The principal

62 components of this complex are adenomatous polyposis coli (APC), Axin and Glycogen

63 synthase kinase $3 \beta$ (GSK3 $\beta$ ) (Kramps et al., 2002; Hamada et al., 1999; Salic et al., 
64 2000; Lee at al., 2003). Axin, a critical scaffold protein in the $\beta$-catenin degradation

65 complex, is the rate-limiting factor of Wnt signaling and its protein levels are regulated

66 by the Ubiquitin-Proteasome System (UPS) (Li et al., 2012). Axin is targeted for

67 degradation by the combined action of the poly-ADP-ribose polymerase Tankyrase

68 (TNKS) and the ubiquitin E3-ligase Iduna/Ring finger protein 146 (RNF146) (Zhang et

69 al., 2011). Both genetic and pharmacological studies suggest that UPS-dependent

70 degradation of Axin occurs in a specific temporal order. Iduna initially exists in an

71 inactive state, but binding to its iso- or poly-ADP-ribosylated targets causes allosteric

72 activation of the enzyme (DaRosa et al., 2015). In the first step, TNKS binds to Axin and

73 ADP-ribosylates Axin using $\mathrm{NAD}^{+}$. Then, Iduna recognizes and binds to ADP-

74 ribosylated Axin via its WWE domain and poly-ubiquitylates Axin. Following the ADP-

75 ribosylation and ubiquitination, post-translationally modified Axin is rapidly degraded by

76 the proteasome (DaRosa et al., 2015; Wang et al., 2016a and 2016b; Croy et al., 2016;

77 Callow et al., 2011). This tight control suggests an important function for Iduna to

78 regulate the Wnt- $\beta$ catenin pathway.

79 Since the stability of Axin is partially regulated by TNKS-mediated ADP ribosylation,

80 specific small-molecule inhibitors have been developed to inhibit Wnt-signaling (Lu et

81 al., 2009; Huang et al., 2009). For example, XAV939 targets the ADP-ribose

82 polymerase activity of TNKS and increases Axin levels, which in turn destabilizes $\beta$ -

83 catenin to inhibit Wnt signaling (Huang et al., 2009). There are two TNKS isoforms in

84 mammalian cells (Hsiao et al., 2006). Tnks $1^{-/-}$and Tnks2 ${ }^{-/-}$mice are overall normal;

85 however, double knock-out of $T n k s^{1 / 2}$ causes early embryonic lethality, which indicates

86 their redundancy in mouse development (Hsiao et al., 2006; Chiang et al., 2008). On 
87 the other hand, inactivation of the single Drosophila Tnks gene produces viable flies that

88 have slightly increased Axin levels and abnormal proliferation of intestinal stem cells,

89 but otherwise display no overt defects (Wang et al., 2016a and 2016b; Feng et al.,

90 2014; Yang et al., 2016; Tian et al., 2016). On the other hand, the exact physiological

91 function of Iduna remains to be determined. In order to address this question, we

92 generated and characterized Drosophila Iduna loss-of-function mutants and

93 demonstrate a critical function of this pathway for stem cells in the Drosophila intestinal

94 tract.

95 The Drosophila genomes encode four isoforms of CG8786/lduna/RNF146, which is

96 evolutionarily conserved from Drosophila to human. In this study, we concentrated on

97 the physiological function of Iduna in the adult Drosophila midgut, which shares several

98 striking similarities with the mammalian small intestine but offers greater anatomical and

99 genetic accessibility (Micchelli et al., 2005; Ohlstein et al., 2005; Markstein et al., 2013).

100 Under normal conditions, Wingless signaling controls stem cell proliferation and cell fate

101 specification in adult midgut (Tian et al., 2016). Here, we show that Iduna has a 102 physiological function to regulate the proteolysis of both TNKS and Axin. Inactivation of 103 Iduna results in increased numbers of midgut stem cells and progenitors due to over104 proliferation. We find that Axin accumulation in enterocytes promotes the secretion of 105 Unpaired, a cytokine that binds to the Domeless receptor and activates the JAK-STAT 106 pathway in stem cells and thereby promotes stem cell division. Significantly, reducing 107 Axin expression by half restores the numbers of ISC. These findings indicate that 108 regulation of Axin proteolysis by Iduna is necessary to control intestinal homeostasis in 
bioRxiv preprint doi: https://doi org/10.1101/296830; this version posted January 15,2019 . The copyright holder for this preprint (which was not certified by peer review) is the author/funder, who has granted bioRxiv a license to display the preprint in perpetuity. It is made available under aCC-BY-NC-ND 4.0 International license.

109 Drosophila, and it provides physiological evidence for the idea that the function of Tnks

110 and Iduna/RNF146 is tightly coupled.

111 


\section{Results}

113 Iduna plays a role in Axin degradation: To examine the in vivo function of Drosophila

114 Iduna, CRISPR-Cas9 genome editing was used to generate Iduna mutants. Iduna is

115 located on the $3^{\text {rd }}$ chromosome of Drosophila. We designed a specific guide RNA that

116 targets Iduna`s first exon and identified two mutant alleles by Sanger sequencing:

117 Iduna ${ }^{17}$ and Iduna ${ }^{78}$, which have 4-nucleotides and 2-nucleotides deletions, respectively

118 (Fig 1A). These deletions are close to the translation start side of Iduna. Next we

119 assessed the levels of mRNA and protein expression in these mutants. Using reverse

120 transcript PCR analysis, we found significantly reduced amounts of Iduna transcripts in

121 the Iduna ${ }^{78}$ mutant. On the other hand, we were unable to detect any Iduna $B$ and $C / G$

122 transcripts in the Iduna ${ }^{17}$ allele (Fig S1A). Moreover, no Iduna protein was detected in

123 either of these mutants, indicating that they represent Null-mutations (Fig 1B). Finally,

124 genetic analyses of these alleles in trans to a larger deletion (see below) indicate that

125 both alleles are complete loss-of-function mutations. Iduna mutants were crossed to

126 Drosophila deficiency lines [Df(3L) Exel6135, Df(3L) ED228)] and also to each other

127 and all combinations were viable as trans-heterozygotes.

128 We examined the larval development of Iduna mutants and Oregon $\mathrm{R}$ but did not

129 observe any differences in the numbers of hatched eggs (Fig S1B-C), pupated larvae

130 and enclosed adult Drosophila (Fig S1D) between Iduna mutants and wild type. Iduna-

131 Null adult flies had no overt morphological defects when compared with wild type

132 controls. However they displayed increased mortality upon nutrient deprivation. We

133 challenged mutant and wild type adult females with a $5 \%$ sucrose diet at $28^{\circ} \mathrm{C}$. Two- 
134 day old adult females were placed on $5 \%$ sucrose diet at $28^{\circ} \mathrm{C}$. Mutant flies died within

13517 days, while $70-80 \%$ of wild type flies were still viable at this time (Fig 1 C).

137 Iduna is one of the key components of the machinery that degrades Axin whose ADP-

138 ribosylation by TNKS is important for mammalian Wnt- $\beta$ catenin signaling (Li at al., 139 2012). We detected increased levels of endogenous Axin in the lysates from Iduna 140 mutants midguts compared to controls (Fig 2A). Mammalian Iduna recognizes both 141 ADP-ribosylated (ADPR) TNKS and Axin via the R163 residue in its WWE domain 142 (Zhang et al., 2011). The R163 residue is conserved in evolution and corresponds to 143 R252 in the Drosophila WWE domain (Fig 2B). To examine the level of endogenous 144 ADPR-Axin in Iduna mutants, ADPR-Axin was pulled down with wild type-WWE or 145 R252A-WWE-mutant recombinant proteins (Fig 2C). This analysis revealed that Iduna 146 mutants had a more than two-fold increase in ADPR-Axin in their midgut compared to 147 wild type (Fig 2D-E). These suggest that Iduna promotes Axin degradation in vivo.

148 To further understand the contribution of Iduna inactivation for both TNKS and Axin 149 proteolysis in Drosophila, UAS-Flag-TNKS and UAS-GFP-Axin transgenes were misexpressed under an eye-specific driver, GMR, in an Iduna mutant background (Fig 151 S2A). To detect mis-expressed GFP-Axin and flag-Tankyrase levels, total proteins were 152 extracted from five day-old male heads and analyzed by immunoblotting (Fig S2C and 153 E). We found that Iduna mutants had 2.5-fold more mis-expressed GFP-Axin protein 154 when compared to the control (Fig S2D). These mutants had 3.5-fold more ectopic 155 expressed flag-tagged Tankyrase as well (Fig S2F). When we examined the eye 156 morphology, GFP-Axin mis-expression did not cause obvious eye phenotype (Fig S2A). 
157 On the other hand, mis-expressed flag-tagged Tankyrase led to rough eyes. This

158 phenotype was more severe when Tnks was mis-expressed in Iduna ${ }^{-/}$homozygous

159 mutants compared to Iduna ${ }^{-/+}$heterozygous animals. (Fig S2B). Recently, it was also

160 reported that mis-expressed Tankyrase promotes apoptosis in the Drosophila eye due

161 to the activation of JNK signaling (Feng et al., 2018).

162 In order to examine whether Axin is a target for Iduna-mediated degradation, we also

163 mis-expressed a UAS-GFP-Axin transgene under the enterocyte specific temperature

164 sensitive Myo1A-Gal4 driver (Fig S3A) and saw 2-2.5 fold more Axin in Iduna mutants

165 compared to controls (Fig S4B). To investigate the cellular levels of Myo1A driven GFP-

166 Axin in the enterocyes, we examined FRT80B, Iduna mutant clones and found that

167 mutant enterocyte clones had more GFP-Axin when compared to their neighboring cells

168 (Fig S4C). Taken together, these observations suggest that Iduna plays a role in

169 promoting the degradation of both Axin and TNKS.

170 Iduna is required to control the proliferation of intestinal progenitors in the

171 Drosophila midgut: Attenuations in the Wingless pathway cause over-proliferation of

172 stem cells in the Drosophila midgut. For instance, inactivation of Tcf, arr, armadillo, dsh,

173 and pygo leads to suppression of Wingless signaling, which in turn causes more stem

174 cell division (Kramp et al., 2002; Wang et al., 2016a and 2016b; Tian et al., 2016). On

175 the other hand, Apc and Tnks mutations cause elevation of Axin, reduce wingless

176 signaling and mitosis of stem cells in Drosophila (Wang et al., 2016a and 2016b; Tian et

177 al., 2016). Hence, the Wingless signaling pathway is required to control intestinal stem

178 cell proliferation in Drosophila (Xu et al, 2011; Cordero et al., 2012; Tian et al., 2016). 
179 Since Iduna mutants have elevated Axin level, we considered that Iduna inactivation

180 may cause aberrant proliferation of stem cells in the Drosophila midgut. Just as the

181 mammalian intestine (Korinek et al., 1998), the Drosophila midgut has intestinal stem

182 cells (ISCs) which give rise to all intestinal compartments (Micchelli et al., 2005;

183 Ohlstein et al., 2005). ISCs give rise to two types of daughter progenitor cells:

184 undifferentiated enteroblasts (EBs) and pre-enteroendocrine cells (Pre-EE). EBs and 185 pre-EEs differentiate into enterocytes (ECs) and enteroendocrine (EEs) cells, 186 respectively (Ohlstein et al., 2005; Xu et al., 2011) (Fig S4A). Stem cells can be 187 distinguished from enterocytes by their cell size and marker proteins (Ohlstein and 188 Spadling 2006; Xu et al., 2011). Stem cells are small, express cell membrane189 associated Armadillo, and lack of nuclear Prospero (Fig S4B). In contrast, nuclear 190 Prospero staining is a marker of small-sized differentiated enteroendocrines (Fig S4B).

191 ISCs are also marked by the expression of escargot (esg), a transcription factor whose 192 GFP reporter allows tracing of stem and progenitor cells during development (Ohlstein 193 et al., 2005) (Fig S4B). Using the esg>GFP marker, we first analyzed 9 day-old female 194 flies which were fed with a $5 \%$ sucrose diet for seven days at $28^{\circ} \mathrm{C}$ and saw an 195 approximately twofold increase in the numbers of escargot positive ISCs/progenitors in 196 the midgut of Iduna mutants compared to controls (Fig 3A-B). Iduna inactivation 197 increased the numbers of $\mathrm{Arm}^{+} / \mathrm{Pros}^{-}$stem cells in the midguts (Fig 3C) upon nutrient 198 deprivation.

199 To test whether the increased number of ISCs was dependent on nutrient deprivation, 200 we examined midguts of seven-day old female mutants and controls on regular diet. We 201 saw again an approximately twofold increase in the numbers of both escargot>GFP 
202 positive (Fig 3D-E) and Arm $^{+} /$Pros $^{-}$stained (Fig 3F-G) stem cells-progenitors under

203 these conditions. Therefore, increased ISC numbers in Iduna mutants are independent

204 of diet.

205 To exclude the possibility that Iduna mutant flies raised on regular diet had reduced 206 nutrient uptake, we monitored fly feeding by an acid blue 9 colorimetric assay (Mattila et 207 al., 2018). We noticed no decrease in food intake in Iduna mutants kept on regular diet 208 at $24-25^{\circ} \mathrm{C}$ compared to controls (Fig S1E). These results show that Iduna inactivation 209 promotes the numbers of midgut stem cells independent of diet and food intake. Finally, 210 we analyzed the midgut cell composition in Iduna mutant and control flies. We 211 observed a slight increase in the total midgut cell number of Iduna mutants (Fig S4C).

212 However, there were no significant differences in the number of EC and EE cells (Fig 213 S4D-E). Collectively, these observations indicate that Iduna inactivation selectively 214 affects ISC numbers.

215 The observed increase in stem cell numbers could be the result of aberrant stem cell 216 proliferation or inhibition of their differentiation. To distinguish between these 217 possibilities, we first assessed cell proliferation by dissecting 7 day-old mutant or wild 218 type females. Following an hour EdU-labeling of the dissected midguts, we observed 219 that Iduna mutants had more EdU-positive cells (Fig 4A-C). Moreover, phospho-Ser220 Histone $\mathrm{H} 3(\mathrm{pH}$ ) immunostaining (Fig 4D-E) also revealed a significant increase in $221 \mathrm{pH}^{+}$mitotic cells in the midgut of seven-day old female Iduna mutants (Fig 4D-F). 222 These findings suggest that stem cells undergo increased proliferation in the midgut of 223 Iduna mutants. To address whether there was an inhibition of differentiation in Iduna 224 mutants, we generated FRT80B, Iduna mutant clones (Theodosiou et al., 1998). We 
225 found that ECs and EEs were present in the five-day old female mutant clones,

226 demonstrating that Iduna was not essential for differentiation of ISCs into daughter cells

227 (Fig S4F-G).

228 Regulation of Axin proteolysis by Iduna is necessary for normal ISC proliferation:

229 One possible mechanism by which Iduna may control the proliferation of ISCs in the

230 Drosophila midgut is through modulating the concentration of Axin. To determine

231 whether a reduction of the elevated Axin levels could reduce ISC numbers in Iduna

232 mutants, they were recombined with Axin mutants and then crossed again with Iduna

233 mutants to generate flies that were homozygous mutant for Iduna $^{-/}$and heterozygous

234 for $\mathrm{Axin}^{+/-}$. Strikingly, a reduction of the Axin gene dosage by $50 \%$ restored ISC

235 numbers to wild type levels in Iduna mutants (Fig 5A). Compared to seven day-old

236 female controls, Iduna mutants had an approximately twofold increase in the number of

$237 \mathrm{Arm}^{+} / \mathrm{Pros}^{-}$as well as $\mathrm{pH}^{+}$mitotic stem cells (Fig 5B-C). On the other hand, reducing

238 the Axin gene dosage by $50 \%$ in an Iduna-Null background yielded numbers of ISCs

239 and the $\mathrm{pH}^{+}$stem cells comparable to seven day-old wild type females. These results

240 suggest that small changes in the levels of Axin have profound effects on stem cell

241 number, and that regulation of Axin degradation by Iduna is necessary for normal ISC

242 proliferation.

243 We observed that Iduna mutants had 2-fold more Axin in the Drosophila midgut. This

244 indicates that defects in Axin degradation may cause over-proliferation of stem cells due

245 to inhibition of wingless signaling. Therefore, we analyzed a reporter for the Wingless

246 pathway target gene, frizzled-3 (fz3). It was previously reported that $f z 3-R F P$ reporter

247 activity is high at the major boundaries between compartments (Buchon et al., 2013; 
248 Tian et al., 2016; Wang et al., 2016a, b). Fz3-RFP was strongly expressed in

249 enterocytes at three distinct sites of the midgut: around R1a, R2c, and R5 (Buchon et

250 al., 2013). Therefore, enterocytes are the primary sites of the Wingless pathway

251 activation during intestinal homeostasis (Tian et al., 2016).

252 We analyzed 3 day-old $f z 3-G a l 4>$ GFP expressing females and consistently observed

253 that $f z 3>$ GFP was expressed in gradients in the foregut, posterior midgut, as well as the

254 border between the posterior midgut and hindgut (Fig 5D). Here, we focused on the

255 posterior midgut-hindgut border to investigate the effect of Iduna on wingless signaling.

256 Upon $f z 3-G a l 4$ driven RNAi-mediated Iduna depletion, we found that $f z 3>$ GFP activity

257 decreased significantly (Fig 5E). We conclude that Iduna stimulates wingless activity in

258 the posterior midgut by promoting degradation of Axin.

259 The proliferation of stem cells in the Drosophila midgut is regulated by intrinsic signals

260 and also interactions with neighboring cells (Zhou et al., 2013; Tian et al., 2016). To

261 further investigate whether the observed effects could reflect a cell-autonomous

262 requirement of Iduna in stem cells, or alternatively a requirement in other cells of the

263 midgut, Iduna was specifically targeted in enterocytes as well as midgut stem and

264 progenitors cells by using the Myo1A-Gal4 and esg-Gal4 drivers, respectively (Fig 6A-

265 B). We examined 7 day-old females expressing Iduna RNAi under the Myo1A or esg

266 drivers. RNAi-mediated knock-down of Iduna in enterocytes caused a significant

267 increase in $\mathrm{Arm}^{+} / \mathrm{Pros}^{-}$stem cell numbers (Fig 6B). However, stem cell/progenitor cell-

268 specific knock-down of Iduna did not affect either the stem cell numbers or mitosis in the

269 midgut (Fig 6B-C). This suggests that Iduna inactivation causes stem cell over-

270 proliferation by a non cell-autonomous mechanism, and that perhaps enterocytes are 
271 responsible for stem cell over-proliferation in Iduna mutants. To further test this idea,

272 we ectopically expressed Iduna in enterocytes and investigated if this could suppress

273 stem cell proliferation in Iduna mutants (Fig 6D). Indeed, consistent with this model, we

274 saw that Myo1A-Gal4 driven UAS-Iduna was able to restore normal numbers of stem

275 cells and progenitors (Fig 6E-F). Taken together, our results indicate that Iduna plays a

276 physiological role to regulate wingless signaling in enterocytes, which is critical for

277 proper ISC proliferation.

278 We found that Iduna mutants have increased mortality upon nutrient deprivation (Fig.

$2791 \mathrm{C})$. Following 7 days on a $5 \%$ sucrose diet at $28^{\circ} \mathrm{C}$, Iduna mutants had more esg $>$ GFP

280 positive cells in the midgut (Fig 3A-C). Therefore, we considered that under reduced

281 nutrient diet, hyper-proliferation of midgut stem cells may be responsible for elevated

282 mortality. To test this idea we first inactivated Iduna in enterocytes by expression of

283 three different RNAi lines under the Myo1A driver. We found that RNAi-mediated Iduna

284 depletion did not increase lethality compared with white RNAi (Fig S5A). There was also

285 no significant change on the mean lifespan between white and Iduna RNAi expressing

286 flies (Fig S5B). We also tested enteroblast specific Iduna depletion and again found no

287 significant effects on longevity upon nutrient deprivation (Fig S5C). Finally, we

288 expressed UAS-Iduna transgene under Myo1A driver in enterocytes to rescue the

289 elevated mortality in the mutants. Whereas the Iduna transgene rescued the hyper-

290 proliferation phenotype (Fig S5E), it failed to rescue the mortality of mutants on 5\%

291 sucrose diet (Fig S5D). These findings suggest that Iduna mortality is not caused by

292 dysregulation of midgut stem cell proliferation and point to another role of Iduna in

293 promoting survival under stress conditions. 
Depletion of Iduna promotes stem cell proliferation through the JAK-STAT

pathway: In order to further investigate the mechanism by which Iduna affected ISC proliferation, we explored the function of additional signaling pathways implicated in this system. Because the JAK-STAT pathway has a well-known role in stem cell proliferation (Zeidler et al., 2000; Zoranovic et al., 2013; Zhou et al., 2013; Markstein et al., 2013), we looked for possible effects of Iduna mutants here. We analyzed the JAKSTAT pathway via 10x Stat-GFP reporter line in the midgut (Bach et al., 2007). Under regular physiological conditions, Stat-GFP reporter expression was mainly seen in small sized cell populations in the midgut that appear to represent ISCs for several reasons (Fig S6). First, Prospero-positive enteroendocrine cells were negative for StatGFP (Fig S6A). Second, enterocytes stained with Armadillo were also not expressing 306 the Stat-GFP reporter (Fig S6D). Finally, Delta-lacZ positive but Prospero-negative cells 307 for the most part expressed Stat-GFP. However, a minor population of small sized cells was GFP positive but Delta-lacZ negative (white arrows, Fig S6B). These appear to be undifferentiated progenitors, such as enteroblasts. Seven day-old Iduna mutants had more Stat-GFP positive cells when compared to controls (Fig 7A, S7A-F). We also

311 generated FRT80B, Iduna midgut mutant clones and observed that these clones had 312 elevated JAK-STAT signaling (Fig S7A-B). To confirm elevated JAK-STAT signaling in 313 Iduna mutant stem cells, we stained midguts from seven day-old females for Delta, a 314 previously identified JAK-STAT pathway target gene (Jiang et al., 2009). We found that 315 there was indeed more Delta protein in Iduna mutants, consistent with elevated JAK316 STAT activity (Fig S7G). 
318 To test whether activation of JAK-STAT signaling was responsible for aberrant ISC

319 proliferation, we knocked down stat92E, a transcription factor in the JAK-STAT 320 pathway, in enterocytes as well as in stem cells and progenitors. We did not detect

321 dramatic changes in the numbers of mitotic cells when stat92 transcription factor was

322 depleted in enterocytes (Fig 7B). Interestingly, knock-down of stat92E in midgut stem

323 and progenitors cells was sufficient to suppress their increased cell division (Fig 7B).

324 Collectively, these observations suggest that Iduna inactivation causes decrease in wingless signaling in enterocytes which in turn causes elevated JAK-STAT signaling in 326 midgut stem cells and thereby results in their over-proliferation.

328 Our observations raise the question of how enterocytes signal ISC proliferation. One 329 possibility is that enterocytes secrete a factor activating the JAK-STAT pathway in stem 330 cells. The JAK-STAT pathway can be activated by cytokines, such as unpaired (UPD, 331 UPD2, UPD3) in the Drosophila midgut (Ghiglione et al., 2002; Zhou et al., 2013). Upd3 332 is produced in differentiated ECs and in differentiating enteroblasts (Zhou et al., 2013).

333 Therefore, we explored the possibility that unpaired cytokines could mediate stem cell 334 over-proliferation in Iduna mutants. For this purpose, we first inactivated Iduna with the 335 Upd3-Gal4 driver and found that RNAi-mediated knock-down of Iduna resulted in a 336 significant increase of Upd3>GFP reporter expression in the midgut (Fig 7C-D, Fig 337 S8A). Upd3>GFP-positive cells were mainly enterocytes, and not EEs or ISCs (Fig 7E, 338 Fig S8B-C). We then knocked down Iduna in enterocytes and performed a q-PCR to 339 test whether Iduna depletion in enterocytes induced unpaired expression. We detected 
340 that enterocyte specific Iduna inactivation resulted in elevated Upd3 gene expression

341 compared to white RNAi (Fig 7D). To suppress the over-proliferation of midgut stem cell

342 in Iduna mutants, we finally reduced Upd2 and Upd3 gene dosages. Strikingly, we

343 found that heterozygosity in $\Delta U p d 2-U p d 3$ fully suppressed ISC proliferation in Iduna

344 mutants (Fig. 7E). Secreted Unpaired proteins bind to the Domeless receptor on ISCs

345 (Ghiglione et al., 2002). Therefore, we tested whether decreasing Domeless levels

346 could also suppress stem cell over-proliferation in Iduna mutants. Again, this prediction

347 was experimentally confirmed (Fig 7E). We conclude that inactivation of Iduna causes

348 decrease in wingless signaling in enterocytes, which in turn leads to increased secretion

349 of UPD2-3 from these cells to stimulate over-proliferation of ISCs through the JAK/STAT 350 pathway (Fig 7F).

\section{Discussion}

353 In this study, we investigated the in vivo function of Iduna and identified a critical role of 354 this enzyme for the control of stem cell proliferation in the Drosophila midgut. It was 355 previously shown that mammalian Iduna is an unusual E3-ubiquitin ligase that 356 specifically binds to and poly-ubiquitylates ADP-ribosylated substrates to promote their 357 rapid degradation by the proteasome. However, the physiological function of Iduna 358 remains largely unclear. Here, we generated Drosophila Null-mutants and used them to 359 show that Iduna has an important in vivo function for the degradation of ADP-ribosylated 360 TNKS and Axin to control stem cell proliferation. In particular, we focused on the role of 361 Iduna in the Drosophila midgut. We found that Iduna inactivation caused a slight but 362 significant increase in Axin protein levels in enterocytes, which in turn caused over- 
363 proliferation of intestinal stem cells. This non-cell autonomous effect on stem cell

364 proliferation was depended on UPD2-UPD3 cytokines that are secreted from

365 enterocytes. These findings suggest a model in which loss of Iduna function, which

366 decreases the Wingless pathway activity due to elevated Axin levels in enterocytes,

367 which in turn causes increased secretion of UPD2-3 resulted from these cells to activate

368 the JAK-STAT pathway in ISCs. Importantly, a 50\% reduction in Axin gene dosage

369 blocked the over-proliferation of stem cells in Iduna mutants, demonstrating the

370 necessity to tightly regulated Axin levels in this system. Whereas many other cell types

371 appear to tolerate fluctuations in the amount of Axin protein, proper wingless signaling

372 in the Drosophila midgut appears to critically depend on restricting Axin levels by Iduna.

373 The activity of Iduna depends on binding to ADP-ribosylated substrates via its WWE

374 domain. Recognition and binding to its ADP-ribosylated target proteins change the

375 structural confirmation of Iduna. Subsequently, Iduna is activated to ubiquitylate its

376 targets for proteasome-mediated degradation. It was previously reported that TNKS

377 forms a tight complex with Iduna to control the proteolysis of target proteins (DaRosa et

378 al., 2015). We could not detect any obvious morphological differences between Iduna

379 mutants and wild type. Although this may seem somewhat surprising, it is consistent

380 with inactivation of Tnks in Drosophila, which also causes no overt abnormalities (Feng

381 et al., 2014; Wang et al., 2016a and 2016b; Yang et al., 2016). Like for Iduna, Tnks

382 mutants have no obvious effects on wing development and the expression of wingless

383 target genes in larval wing discs, despite the fact that Axin levels are increased (Feng et

384 al., 2014; Wang et al., 2016a and 2016b; Yang et al., 2016). Our interpretation of these

385 findings is that most tissues can tolerate relative modest (2-3-fold) changes of Axin. For 
example, it appears that a greater than 3-fold increase of endogenous Axin is required

387 for functional consequences of altered wingless signaling in Drosophila embryos (Yang et al., 2016) and 3-9-fold changes are needed in wing discs (Wang et al., 2016a). On

389 the other hand, the Drosophila midgut appears much more sensitive to reduced Wingless signaling.

391 A recent study demonstrated that inactivation of Drosophila Tankyrase (Tnks) also led 392 to increased Axin protein accumulation in the Drosophila midgut and promoted ISC 393 proliferation as well (Wang et al., 2016). These results are consistent with previously 394 reported cell-based studies suggesting that Iduna mediates Tankyrase-dependent 395 degradation of Axin and thereby positively regulates Wnt signaling (Huang et al., 2009; 396 Zhou et al., 2011; Croy et al., 2016; Callow et al., 2011). On the other hand, it is 397 somewhat surprising that inactivation of two highly diverse types of enzymes, 398 Tankyrase, a poly-ADP-ribose polymerase versus Iduna, a ubiquitin E3 ligase, produces remarkably similar phenotypes. Both Tnks and Iduna have many other targets outside 400 the Wnt-pathway, and based on biochemical observations it has been proposed that 401 they may play roles in DNA repair, telomere length, vesicle trafficking, Notch-signaling, 402 centrosome maturation, neuronal protection and cell death (Bai et al., 2012; Gibson et 403 al., 2012; Riffel et al., 2012). However, Iduna mutant flies are viable and do not show 404 any obvious defects under normal growth conditions. This indicates that the major non405 redundant physiological function of both Tnks and Iduna in Drosophila is to regulate 406 Wingless-mediated intestinal stem cell proliferation, and that it provides physiological 407 evidence for the idea that the function of both proteins is indeed tightly coupled. In 408 addition, our study identifies a role of Upd/Dome in this pathway. These results may 
409 also have implications for the regulation of this highly conserved pathway in mammals.

410 For example, conditional inactivation of Iduna in mouse bones leads to increased

411 numbers of osteoclasts and inflammation (Matsumoto et al., 2017a). In this system,

412 down-regulation of Iduna leads to accumulation of Axin1 and 3BP2. This, in turn,

413 attenuates $\beta$-catenin degradation and activates SRC kinase, respectively, thereby

414 promoting the release of inflammatory cytokines in the bone (Matsumoto et al., 2017a).

415 On the other hand, Iduna depletion reduces proliferation of osteoblasts and promotes

416 adipogenesis in the mouse skeleton (Matsumoto et al., 2017b). Despite the obvious

417 differences between mammalian bone and the Drosophila midgut, both systems show

418 overall striking similarities in the use of TNKS/Iduna to restrict Axin levels to achieve

419 proper levels of Wnt/ $\beta$-catenin signaling during tissue homeostasis. Finally, our study

420 also indicates that Axin may have a more general function as a scaffold protein to

421 recruit multiple proteins to permit a crosstalk with other pathways to modulate Wnt/ $\beta$ -

422 catenin signaling.

423 


\section{$424 \quad$ Figure Legends}

425 Figure 1: Loss-of-function mutants of dlduna are viable and increase TNKS and

426 Axin protein levels. A- Iduna ${ }^{17}$ and $I d u n a^{78}$ have deletions of 4 and 2 nucleotides,

427 respectively, introduced early stop codons and led to truncations of Iduna protein.

428 Scheme for generation of Iduna loss-of-function mutants via CRISPR-Cas9 genome

429 editing in Drosophila. sgRNA against Iduna was designed to generate small nucleotide

430 deletions, close to its translation initiation site. The three nucleotides were highlighted

431 with red to indicate the location of Cas9 cleavage site. Iduna loss-of-function mutants,

432 Iduna ${ }^{17}$ and Iduna ${ }^{78}$, were isolated by Sanger sequencing. B- Iduna ${ }^{17}$ and Iduna ${ }^{78}$ have

433 no detectable protein. Endogenous Iduna protein was detected by immunoblotting. Anti-

434 Iduna antibody was generated in guinea pigs and $20 \mu \mathrm{g}$ total protein lysates of seven

435 day-old adult females were analyzed by immunoblotting. $\beta$-actin was used as a loading

436 control. Both Iduna alleles have no detectable protein and behave genetically as Null-

437 alleles. C- Iduna mutants display increased mortality under reduced nutrient conditions.

438 Two-day old mutant or wild type female flies were collected and kept on $5 \%$ sucrose

439 diet at $28^{\circ}$ C. $n=100$ from each genotype. D- There is an approximately twofold increase

440 in the numbers of esg $>$ GFP expressing stem cells/progenitors in the midgut of Iduna

441 mutants compared to controls. E- Quantification of esg>GFP positive stem cells and

442 progenitors from adult flies of indicated genotypes. $\mathrm{n}=6$ from each genotype. F- Iduna

443 inactivation increases the numbers of $\mathrm{Arm}^{+} / \mathrm{Pros}^{-}$stem cells in the midguts upon nutrient 444 deprivation. Nine day-old female flies, fed with $5 \%$ sucrose diet for seven days at $28^{\circ} \mathrm{C}$,

445 were examined in D-E and F. Posterior midguts were analyzed in this study. $p<0.001$ is 446 indicated as ***. 
447 Figure 2: Iduna inactivation causes increased Axin protein levels in the midgut.

448 A- Iduna mutant midguts have elevated Axin protein. Midguts of 7 day-old adult females

449 expressing GFP-Axin under the temperature sensitive Myo1A-Gal4 driver were

450 dissected, lysed and analyzed by GFP immunoblotting. Iduna mutants had more Axin

451 protein compared to the wild type. $20 \mu \mathrm{g}$ total intestinal lysates were analyzed by GFP

452 immunoblotting and $\alpha$-tubulin was used as a loading control. B- Loss-of-lduna resulted

453 in 2.2-fold GFP-Axin accumulation in the midgut. Western blot quantification was

454 performed based on two independent experimental replicates, and protein levels were

455 normalized to $\alpha$-tubulin. $\mathbf{C}$ - Iduna recognizes ADP-ribosylated (ADPR) Axin via the R252

456 residue of its WWE domain. This residue corresponds to R163 in the mammalian Iduna

457 ortholog and is conserved during evolution. Recombinant wild type and R252A mutants

458 were used as biochemical sensors to pull down the ADPR-Axin from Drosophila

459 midguts. Myc-tagged WWE proteins were expressed and purified from Drosophila S2R+

460 cells by immunoprecipitation. D- Inactivation of Iduna leads to accumulation of ADPR-

461 Axin. Wild type myc-tagged-WWE protein pulled down ADPR-Axin. In contrast, the

462 R252A mutant did not interact with modified Axin. Following IP, eluted proteins were

463 analyzed with an $\alpha$-PAR antibody. The $50 \mathrm{kDa}$ heavy chain $\lg \mathrm{G}$ is indicated on the blot.

464 E- Iduna inactivation results in 2.3-fold more ADPR-Axin protein in the midgut. Western

465 blot quantification of two independent experimental replicates; ADPR-Axin levels were

466 normalized to the control lines. Flies were fed with regular diet at $24-25^{\circ} \mathrm{C} . p<0.001$ is

467 indicated as ${ }^{* * *}$ and $p<0.0001$ was marked as $* * * *$.

468 Figure 3: Iduna mutants have increased numbers of intestinal stem and

469 progenitor cells in their midgut. A-B- Inactivation of Iduna promotes the proliferation 
470 of the esg-GFP labeled progenitor cells in the Drosophila midgut. Intestinal stem and

471 progenitor cells were visualized with a esg>GFP reporter construct. C- Quantification of

472 esg $>G F P^{+}$stem cells and progenitors from adult flies of indicated genotypes. D- In wild

473 type, $25-30 \%$ of posterior midgut cells are stem cells, as assessed by esg $>$ GFP

474 expression. On the other hand, $55-60 \%$ of the total cell population in Iduna mutants

475 expressed the stem marker esg>GFP, representing a greater than two-fold increase. E-

476 F- Iduna mutants have more Arm $^{+} / \mathrm{Pros}^{-}$intestinal stem cells in the midgut. ISCs and

477 enterocytes were distinguished by their cell size, high level of membrane-associated

478 Armadillo, and lack of nuclear Prospero staining. In contrast, small-sized differentiated

479 enteroendocrines were recognized by nuclear Prospero staining. Posterior midguts

480 were analyzed by confocal microscopy following staining for anti-Armadillo, Prospero

481 and DAPI. G-H Quantification of Arm ${ }^{+} /$Pros $^{-}$ISCs from adult flies of indicated genotypes.

482 The midguts of seven day-old adult females were dissected and analyzed by confocal

483 microscopy. For the consistency, posterior midgut R5 region was analyzed in this study.

484 Iduna ${ }^{17 /+}$ flies were used as control. Flies were fed with regular diet at $24-25^{\circ} \mathrm{C} . \mathrm{n}>12$

485 from each genotype. $p<0.001$ was indicated as *** and $p<0.0001$ was marked as ***.

486 Figure 4: Iduna inactivation enhances proliferation of intestinal stem cells. A-B-

487 Genetic depletion of Iduna leads to over-proliferation of intestinal stem cells in the 488 midgut. EdU was used as a proliferation marker and administrated for $1 \mathrm{~h}$ at $25^{\circ} \mathrm{C} .7$ 489 day-old mutants or wild type female flies were dissected for analysis. Following fixation, 490 EdU incorporation was analyzed by confocal microscopy. C- Increased numbers of $491 \mathrm{EdU}^{+}$stem cells were seen in Iduna mutants, indicating increased cell proliferation. 492 Posterior midguts were analyzed for quantification. D-E- Iduna mutants display elevated 
493 phospho-Ser-Histone 3 (pH3)-positive ISCs. F- Iduna inactivation leads to an increase

494 of $\mathrm{pH}^{+}$mitotic stem cells in the midgut. Quantification of $\mathrm{pH}^{+}$proliferating cells was

495 done in the whole midgut. 7 day-old mutants or wild type female flies were examined.

496 Flies were fed with regular diet at $24-25^{\circ} \mathrm{C} . \mathrm{n}>12$ from each genotype. $p<0.0001$ was

497 marked as ****.

498 Figure 5: A $50 \%$ reduction of Axin restores ISC numbers in the Drosophila

499 midgut. A- Reducing the Axin gene dosage by half restores the number of Arm $^{+} / \mathrm{Pros}^{-}$

500 ISCs. Axin mutants AxinS044230 and AxnE77 were recombined with the Iduna ${ }^{17}$ mutant

501 allele. AxinS044230 is a complete Axin-Null mutant, and AxinE77 is a loss-of-function

502 truncation allele (Q406X). Midguts of 7d-old adult females of the indicated genotypes

503 were dissected and analyzed by confocal microscopy following Armadillo, Prospero and

504 DAPI staining. Axin ${ }^{+/}$, Iduna ${ }^{17 /+}$ served as control. Reducing the Axin gene dosage by

$50550 \%$ in Iduna ${ }^{17 / 17}$ mutants decreased the number of ISCs to normal levels. B-

506 Quantification of ISC numbers. Reducing the Axin gene dosage by half fully suppressed

507 the increased numbers of Arm $^{+} /$Pros $^{-}$ISCs in Iduna ${ }^{17 / 17}$ Null-mutants. C- Reducing Axin

508 gene expression suppressed the proliferation of ISCs in the Iduna ${ }^{17 / 17}$ Null-mutant.

$509 p<0.0001$ was marked as ${ }^{* * * *}$. D- Frizzled $3(f z 3)$ is a wingless target gene and a GFP-

510 reporter construct was used here to visualize Wg-activity in the midgut (Buchon et al.,

511 2013; Tian et al., 2016; Wang et al., 2016a, b). In wild type, $f z 3>G F P$ is highly

512 expressed in a graded fashion in the foregut $(f)$, the posterior midgut $(p)$ as well as the

513 posterior midgut-hindgut border, but not in the anterior midgut (a) or the hindgut proper

514 (h). Higher magnification image of the $f z 3>$ GFP near the midgut-hindgut boundary. 7-

515 day old female midguts were analyzed. E- fz3-Gal4 driven Iduna depletion inhibits 
516 wingless activity. RNAi-mediated down-regulation of Iduna led to significant reduction of

$517 f z 3>$ GFP; white RNAi served as a control. The arrow indicates the border between the

518 posterior midgut and the hindgut (b). Three day-old female midguts were analyzed.

519 Flies were fed with regular diet at $24-25^{\circ} \mathrm{C}$.

520 Figure 6: Iduna depletion in ECs leads to over-proliferation of ISC. A- Over-

521 proliferation of ISCs in Iduna mutants is non-cell autonomous. RNAi-mediated Iduna

522 knock-down was carried out in the enterocytes, stem cells and enteroblast cells using

523 Myo1A-Gal4 and esg-Gal4 drivers, respectively. B- Knock-down of Iduna in enterocytes

524 using the Myo1A-Gal4 driver led to over-proliferation of $\mathrm{Arm}^{+} / \mathrm{Pros}^{-}$ISCs. In contrast, no

525 changes in ISC proliferation were observed upon down-regulation of Iduna in ISCs

526 using esg-Gal4-driven Iduna RNAi. Myo1A-Gal4>GFP served as a control. C- EC-

527 specific knock-down of Iduna increased the number of $\mathrm{pH} 3^{+}$progenitors. D- Ectopic

528 expression of Iduna in ECs inhibits over-proliferation of ISCs. A UAS-Myc-tagged Iduna

$529 \mathrm{C} / \mathrm{G}$ transgene was generated to perform rescue experiments. E- F- Expression of the

530 UAS-Myc-Iduna C/G transgene with the Myo1A-Gal4 driver resulted in a reduction of

531 the numbers of $\mathrm{Arm}^{+} /$Pros $^{-}$ISCs and $\mathrm{pH}^{+}$mitotic stem cells in the midgut of Iduna

532 mutants. Flies were fed with regular diet at $24-25^{\circ} \mathrm{C} .7$ day-old female midguts were

533 analyzed for ISC and mitotic markers. $p<0.0001$ was marked as ****.

534 Figure 7: Loss of Iduna activates the JAK-STAT pathway non-cell autonomously

535 to promote ISC proliferation. A- Iduna mutants have elevated Stat-GFP signaling in

536 ISCs. 10X-Stat-GFP is a reporter for STAT signaling activity. Iduna mutants displayed

537 strongly increased GFP reporter. 7 day-old females were dissected and the posterior

538 midguts were analyzed. B- Quantification of Stat-GFP expressing midgut cells. C- 
539 Knock-down of the stat93E transcription factor in ISCs and EBs blocks ISC over540 proliferation in Iduna mutants. In contrast, RNAi-mediated depletion of stat92E in ECs

541 did not affect proliferation of ISCs. 7 day-old female midguts were dissected and

542 analyzed. D- Iduna depletion results in upregulation of Upd3 mRNA expression in

543 enterocytes. Myo1A driven Iduna-RNAi and white RNAi expressing 7 day-old females

544 were dissected for their midguts. Total RNA was isolated and cDNA libraries were

545 prepared. Upd3 transcripts were amplified and analyzed by q-PCR. E- RNAi-mediated

546 Iduna down-regulation induces Upd3>GFP reporter activity. Iduna was knocked-down

547 using RNAi driven by Upd3-Gal4, and GFP was used as a reporter for Upd3 gene

548 expression. Enterocytes were stained with $\alpha$-Armadillo antibody. EEs and ISCs were

549 negative for Upd3>GFP expression. white RNAi served as a control. 3 day-old female

550 flies were dissected and their posterior midguts were analyzed by confocal microscopy.

551 E- Reduction of either Upd2 and Upd3 or their receptor Domeless suppresses over-

552 proliferation of ISCs in Iduna mutants. Upon reduction of Upd2 and Upd3 gene dosage

553 in Iduna mutants, we observed significantly less mitotic stem cells in Iduna mutants,

554 comparable to WT levels. Likewise, a 50\% reduction of Domeless resulted in

555 suppression of ISC over-proliferation in Iduna mutants. On the other hand, these

556 reductions in gene dosage of Upd2, Upd3 and Dome did not affect mitosis of ISCs in a

557 WT background. 7 day-old female midguts were quantified by $\mathrm{pH}^{+}$staining. Flies were

558 fed with regular diet at $24-25^{\circ} \mathrm{C} . \mathrm{n}>12$ from each genotype. $p<0.0001$ was marked as

$559 * * *$. G- Model for the role of Iduna in the regulation of intestinal stem cell proliferation.

560 Our model suggests that inactivation of Iduna causes Axin elevation which in turn

561 decreases wingless signaling activation in enterocytes, and increases secretion of UPD 
bioRxiv preprint doi: https://doi org/10.1101/296830; this version posted January 15,2019 . The copyright holder for this preprint (which was not certified by peer review) is the author/funder, who has granted bioRxiv a license to display the preprint in perpetuity. It is made available under aCC-BY-NC-ND 4.0 International license.

562 cytokines from these cells. These cytokines activate JAK-STAT signaling through the

563 Dome receptor on neighboring ISCs and thereby induce ISC proliferation in the

564 Drosophila midgut.

565 


\section{Material and Methods}

567 Fly stocks: Flies were kept at a 12-hour light/dark cycle. All crosses were performed at

$56822-25^{\circ} \mathrm{C}$ unless stated otherwise. The following fly stocks were used for this study

569 (Bloomington Drosophila Stock Center (BDSC) and Vienna Drosophila Resource Center

570 (VDRC) number (\#) given in parentheses):

571 The stocks used in here: Df(3L)Exel6135 (BDSC\# 7614), Df(3L)ED228 (BDSC\#

572 8086), Df(3L)ED229 (BDSC\# 8087), esg-Gal4, UAS-GFP (a gift of Dr. Norbert

573 Perrimon, Micchelli et al., 2006), esgK606 (a gift of Dr. Norbert Perrimon, Micchelli et

574 al., 2006), 10X STAT-GFP, Bach et al., 2007), UAS-GFP-Axin (BDSC\# 7224), FRT82B,

575 Axin044230 ( a gift of Dr. Wei Du, Hamada et al., 1999), FRT82B, AxinE77 (a gift of Dr.

576 Jessica Treisman, Collins et al., 2000), Myo1A-Gal4, tub-Gal80ts, UAS-GFP (a gift of

577 Dr. Norbert Perrimon, Micchelli et al., 2006), Upd3-Gal4, UAS-GFP (a gift of Dr. Norbert

578 Perrimon, Markstein et al., 2013), $\Delta$ Upd2/3 (BDSC\# 129), $\Delta$ Dome (BDSC\# 12030),

579 UAS-stat92E RNAi (BDSC\# 26889), UAS-CG8786/dlduna RNAi\#1 (BDSC\# 40882),

580 UAS-CG8786/dlduna RNAi\#2 (VDRC\#43533), UAS-CG8786/dlduna RNAi\#3

581 (VDRC\#36028), UAS-CG8786/dlduna RNAi\#4 (VDRC\#36029), and white RNAi

582 (BDSC\#33623), fz3-Gal4 (BDSC\#36520). The rest of Drosophila lines, which were

583 studied here, were obtained from Steller Lab stocks. Oregon R flies were used as

584 control and only adult female flies were analyzed in this study.

585 Drosophila egg collection: A $10 \mathrm{~mm}^{2}$ apple-agar plate was set up with embryo 586 collection cage to provide a substrate for egg laying. Prior to adding the plate, a small

587 quantity of yeast paste was smeared onto the center of the apple-agar. To provide 588 moisture, water soaked tissue paper was layered under embryo collection cages. 10-15 
589 day old adult flies were collected to the cage, which were then placed into a fly

590 incubator for 4 hours. Then, laden eggs were counted and 50 of them were plated into

591 one corner of $10 \mathrm{~cm}^{2}$ apple-agar plates, in which had a straight yeast paste smear at the

592 center. Agar plates finally were incubated in the incubator. After $24 \mathrm{~h}$, hatched eggs

593 were counted.

594 To analyze larval development, hatched $1^{\text {st }}$ instar larvae were counted and placed into a

595 fresh yeast paste containing agar plate until they were reached to $3^{\text {rd }}$ instar larvae. After

596 counting, larvae were placed into regular food containing vials. They were counted two

597 rounds when they pupated and enclosed.

$5985 \%$ sucrose diet: $5 \mathrm{~mm}^{2}$ Whatman filter papers were soaked with $1 \mathrm{ml} 5 \%$ sucrose 599 solution and placed into the empty vials. 5\% sucrose solution was used as reduced 600 nutrient diet. Enclosed adult females were collected at $24-25^{\circ} \mathrm{C}$. When they were 2 day601 old, their regular diet was replaced to $5 \%$ sucrose diet at $28^{\circ} \mathrm{C} .20$ of two day-old wild 602 type or Iduna mutant female flies were grouped and kept on 5\% sucrose solution603 soaked filter paper containing vials at $28^{\circ} \mathrm{C}$. Following the fly count, death flies were 604 removed and $1 \mathrm{ml} 5 \%$ sucrose-embedded filter papers were replaced with a new one 605 everyday.

606 Food intake measurement: Female flies of Iduna mutant and Oregon R were collected 607 after they enclosed. Before measuring food intake, the flies were kept on the regular 608 food for 6 days. The flies then transferred to the regular food supplemented with $0.5 \%$ 609 (w/v) Acid Blue 9 (erioglaucine disodium salt, Sigma 861146) for 4 hours. 610 Quandruplicates of 5 flies per sample were then homogenized in $250 \mu 1$ XPBS and 611 cellular debris was removed by centrifugation. Food intake was quantified by measuring 
612 the absorbance of the supernatant at $630 \mathrm{~nm}$ and normalized to the wet weight of the

613 flies.

614 CG8786/dRNF146/dlduna CRISPR/Cas9 editing: We used the CRISPR optimal target

615 finder website (tools.flycrispr.molbio.wisc.edu/targetFinder) to identify an appropriate

616 guide RNA (gRNA) target sequence within dlduna (Granz et al., 2013 and 2014). We

617 purchased the forward 5`-GTCGCTAGCTGCAATCTGCTCTG-3` and reverse 5`-

618 AAACCAGAGCAGATTGCAGCTAG-3` oligos (IDT, Inc.) annealed, and followed the

619 protocol; from Port et al., 2014 to clone the annealed oligos into pCFD3-dU6:3-gRNA

620 plasmid (Addgene, plasmid\# 49410, Port et al., 2014). Transformants were verified via

621 Sanger sequencing (Genewiz, Inc.). The gRNA plasmid was injected into 300 embryos

622 of custom vasa-Cas9 Drosophila (BestGene, Inc.). The injection was yielded $89 \mathrm{G}_{\circ}$

623 progeny, and we established 70 individual fly lines, a couple of which could possibly

624 have the Iduna loss-of-function mutations.

625 Isolation of the Iduna mutants and genetic mapping of Iduna -loss-of-function

626 mutations: Total DNA was isolated from L3 larvae or 5-days old adults of Iduna

627 homozygous mutants and control sequencing strain using the Roche genomic DNA

628 extraction kit (Roche). To confirm the mutant line, PCR fragments were amplified with

629 specific primers (forward primer 5`-CAGCCCGAGCTGGTCATACTCAG-3, reverse

630 primer 5`-CGGCTTTCTGGGCTACCTAC-3`) binding within 5`UTR of Iduna and within

631 the coding region of the gene. To identify mutation site, the entire coding region was

632 PCR amplified and PCR products were sent for DNA sequencing.

633 Cloning and generation of UAS-CG8786 transgenic Drosophila: Adult flies were 634 directly homogenized in $1 \mathrm{ml}$ TRIzol (Life Technologies) and total RNA was isolated 
635 according to the manufacturer's protocol. cDNA library was prepared from $5 \mu \mathrm{g}$ total

636 RNA, by using oligo(dT) amplification and the Superscript III First Strand synthesis kit

637 (Invitrogen). cDNA library was used to amplify the Iduna transcripts with the primers

638 (forward 5`-ATGTCGCAACAGCGCTCCACAG-3`; Iduna B isoform reverse primer $5^{`}-$

639 TCAGTAGAGCTTTAGGTATACC-3`; Iduna C/G isoform reverse primer $5^{`}-$

640 TCAGTAGAGCTTTAGGTATACCG-3`). Amplified dlduna transcripts were cloned into

641 pUAST (DGRC, Drosophila Genomic Resource Center) and pAc5.1 (Thermo Scientific)

642 vectors by considering the appropriate restriction digestion sites. Following the bacterial

643 transformation, all of the cloned genes were sequenced. To generate UAS-CG8786

644 transgenic Drosophila, myc-tagged pUAST-CG8786/dlduna plasmid was injected into

645 w1118 embryos (Best Gene, Inc.) We obtained successful transgenic lines.

646 Total RNA isolation, cDNA synthesis and Q-PCR: Posterior midguts of 7 day-old

647 adult flies were directly homogenized in $1 \mathrm{ml}$ TRIzol (Life Technologies) and total RNA

648 was isolated according to the manufacturer's protocol (miRNeasy mini kit, QIAGEN).

649 cDNA library was prepared from $5 \mu \mathrm{g}$ total RNA, by using oligo(dT) amplification and the

650 Superscript III First Strand synthesis kit (Invitrogen). cDNA library was used to amplify

651 Upd3 and Rp32I transcripts with the forward 5'-AGGCCATCAACCTGACCAAC-3',

652 reverse $55^{\circ}$-ACGCTTCTCCATCAGCTTGC-3` and forward $5^{`}-$

653 CCCAAGGGTATCGACAACAGA-3`， reverse 5`-CGATCTCGCCGCAGTAAAC-3`

654 primers, respectively. Those primers were designed via the online tool of DRSC/TRiP

655 Functional Genomics Resources, Harvard Medical School and purchased from IDT, Inc. 
657 Cloning and generation of the wild type and mutants UAS-Flag-Tnks transgenic

658 Drosophila: We previously described Drosophila TNKS (Park and Steller, 2013) and its

659 ORF was cloned into pUAST vector from pcDNA3.1-Flag-TNKS. To generate UAS-

660 Flag-TNKS transgenic Drosophila, Flag-tagged pUAST-TNKS plasmid was injected into

661 w1118 embryos (Best Gene, Inc.) We obtained successful transgenic Drosophila lines

662 and those were utilized in conjunction with tissue-specific Gal4 drivers.

663 Clone analysis and RNAi experiments: Mutant clones were utilized to generate

664 mitotic clones. $2^{\text {nd }}$ instar larvae were subjected to an hour heat shock in a $37^{\circ} \mathrm{C}$ water

665 bath per day until they reached the pupa stage and maintained at $24^{\circ} \mathrm{C}$. 3-days old adult

666 females were analyzed.

667 For RNAi experiment, crosses were performed at $24^{\circ} \mathrm{C}$ and the progeny of the desired 668 genotypes were collected on the day of eclosion and maintained at $24^{\circ} \mathrm{C}$ for 7 days 669 before dissection. In the case of using temperature sensitive driver, eclosed virgin 670 females were collected and kept at $29^{\circ} \mathrm{C}$ for 7 days for intestine dissection.

671 Cell culture: S2R+ cells were maintained at $25^{\circ} \mathrm{C}$ in supplemented Grace's Insect 672 Medium (supplemented with $10 \%$ heat inactivated FBS, $100 \mathrm{U} / \mathrm{ml}$ penicillin, $100 \mu \mathrm{g} / \mathrm{ml}$ 673 streptomycin) in spinner flasks.

674 Development of polyclonal antibodies: Full-length GST-tagged-Iduna C/G protein 675 was expressed and purified from BL21 DE3 E.coli strain. Polyclonal antisera were 676 generated in two guinea pigs (Cocalico, Inc.). For Western blot analysis, serum was 677 used in 1:1000 dilutions.

678 Western blot analysis: $50-100 \mu$ dissected tissues or total larvae/flies were lysed in 679 Iysis buffer [50mM HEPES-KOH pH 7.4, 150mM NaCl, 0.05\% Triton-X100, complete 
680 EDTA-free protease inhibitor cocktail (Roche)] using a $1 \mathrm{ml}$ tissue grinder. Lysates were 681 cleared by centrifugation at $13,000 \mathrm{~g}$ for $20 \mathrm{~min}$ at $4^{\circ} \mathrm{C}$. Protein concentrations of 682 supernatants were determined by BCA assay (Pierce). $1 \mu \mathrm{g} / \mu \mathrm{l}$ lysate was prepared with $6833 \mathrm{X}$ sample buffer in $100 \mu$ l total volume $(200 \mathrm{mM}$ Tris-HCl, $\mathrm{pH} 6.8,200 \mathrm{mM}$ dithiothreitol 684 (DTT), 8\% SDS, 24\% glycerol, 0.04\% bromophenol blue), heated at $95^{\circ} \mathrm{C}$ for $10 \mathrm{~min}$ 685 and samples were separated by SDS-PAGE for $1 \mathrm{~h}$ at $120 \mathrm{~V}$, by using standard 1 X SDS 686 Tris base-glycine running buffer. Proteins on the gels were blotted onto a PVDF 687 membrane, in a $1 \mathrm{X}$ transfer buffer (25mM Tris base, 190mM Glycine, 20\% MeOH, $6880.05 \%$ SDS), and transferred (Bio-Rad) at 100V for $90 \mathrm{~min}$. Membranes were taken 689 through a standard immunoblot protocol followed by enhanced chemiluminescent 690 detection (Crescendo ECL, Millipore) using a Lumimager (Fuji, LAS-3000). Primary 691 antibodies: $\alpha$ - tubulin (1/1000, Sigma), $\alpha$-flag (1/1000, Cell Signaling Technologies), $\alpha-$ 692 myc tag (1/1000, Cell Signaling Technologies), GFP (1/2500, Santa Cruz), $\beta$-actin 693 (1/1000), $\alpha$-PAR (1/1000, Trevigen) and $\alpha$-Axin (Feng et al., 2014; dT20 Drosophila 694 Axin antibody, 1/250, Santa Cruz). Secondary antibodies: anti-mouse, anti-rabbit, anti695 guinea pig (1/5000, Jackson Labs).

696 Immunofluorescence: Adult intestines were dissected in 1xPBS and fixed in 4\% 697 paraformaldehyde in PBS for $45 \mathrm{~min}$ at room temperature. Tissues then were first 698 washed with $0.1 \%$ Tween $20-P B S$, second washed with $0.1 \%$ TritonX-100-PBS and 699 finally permeabilized in $0.5 \%$ TritonX 100-PBS for $30 \mathrm{~min}$. Following the blocking with $70010 \%$ BSA in $0.1 \%$ Tween 20 -PBS for $1 \mathrm{~h}$ at room temperature, primary antibody 701 incubation in $10 \%$ BSA in $0.1 \%$ Tween 20 -PBS was performed for overnight at $4{ }^{\circ} \mathrm{C} .3 \mathrm{X}$ $7025 \mathrm{~min} 0.1 \%$ Tween 20-PBS washed intestines then were incubated in secondary 
703 antibodies for $1 \mathrm{~h}$ at room temperature. Specimens were finally mounted in Fluoromount-

704 G (Southern Biotech) and analyzed with confocal imaging. Primary antibodies: mouse 705 anti-Arm (Wang et al., 2016; N2 7A1, DSHB, 1:50), mouse anti-Prospero (Wang et al., 706 2016; MR1A, DSHB, 1/50), mouse anti-GFP (GFP-12A6, DSHB, 1/100), mouse anti- $\beta$ 707 galactosidase (Tian et al., 2016); 401A, DSHB, 1/100), mouse anti-Delta (Wang et al., 708 2016; C594.9B, DSHB, 1/100), rabbit anti-phosho-S10-Histone3 (Wang et al., 2016; 06-

709570, Millipore, 1/1000). The secondary antibodies were Alexa fluorophores (Thermo 710 Fisher Scientific) and diluted as 1/1000.

711 Quantification of Stat-GFP immunostaining intensity: Images from R5 region were 712 taken with a $63 x$ objective. Each STAT-GFP ${ }^{+}$stem cell was identified using Imaris 713 software (Bitplane). The main intensity in those cells within a field (40 $\mu \mathrm{m} \times 40 \mu \mathrm{m})$ 714 surrounding an Iduna mutant clone or an equal field at least $50 \mu \mathrm{m}$ away from the 715 mutant clone was measured. The relative intensity was calculated and shown in the 716 figure (Wang et al., 2016). Statistical analysis was performed with Prism software 717 (GraphPad).

718 Immunoprecipitation: S2R+ cells were seeded at $5 \times 10^{6}$ cells $/ 10 \mathrm{~cm}^{2}$ culture plates 719 and incubated overnight at $25^{\circ} \mathrm{C}$. Cells were then co-transfected with $5 \mu \mathrm{g}$ of each 720 plasmid by using Mirus-insect transfection reagent. Negative control was transfected 721 with empty plasmids. 48 hours later, transfected cells were harvested. The cell pellets 722 were washed within cold 1X PBS. This step was repeated 3 times. Pellets were re723 suspended in $600 \mu 1 \%$ Triton X-100 lysing buffer. Re-suspended pellets were 724 incubated on ice for $15 \mathrm{~min}$ and mixed gently and periodically. Total lysates were 725 centrifuged at $13,000 \mathrm{rpm}$ at $4^{0} \mathrm{C}$ for 30 minutes. The supernatant was removed and 
$726100 \mu \mathrm{l}$ was stored as total lysate. $25 \mu \mathrm{l}$ Protein A/G (Thermo Scientific) beats were

727 washed with lysing buffer for 3 times. $200 \mu$ l supernatant was incubated with the mixture

728 of washed protein A-G beads on a rotator at cold room for 30 minutes. In a parallel way,

$72925 \mu$ l Protein A/G was washed with lysing buffer for 3 times. At the end of incubation

730 period, beads-supernatant mixture was centrifuged at 2,000 rpm at $4^{0} \mathrm{C}$ for 1 minute.

731 Pre-cleaned supernatant was collected and added to beads. Antibody was added to

732 supernatant-beads and incubated at cold room on a rotator for $4 \mathrm{~h}$. Beads-supernatant-

733 antibody mixture was centrifuged at 2,000 rpm at $4{ }^{\circ} \mathrm{C}$ for 1 minute and beads were

734 washed with lysing buffer for 3 times. In the final step, beads were re-suspended in $50 \mu l$

735 of $3 X$ sample buffer to perform immunoblotting.

736 Recombinant protein purification from S2R+ cells: S2R+ cells were seeded at $5 \times 10^{6}$

737 cells $/ 10 \mathrm{~cm}^{2}$ culture plates and incubated overnight at $25^{\circ} \mathrm{C}$. Then, flag or myc-tagged

738 gene of interests were transfected and based on the small tag, a recombinant protein

739 was immunoprecipitated with flag or myc agarose beads as described above. Finally, by

740 using flag or myc peptides, tagged proteins were eluted and quantified by BCA (Pierce,

741 ThermoFisher Scientific).

742 Quantification and statistics: ISC quantification, dissected midguts were stained with

743 Armadillo and Prospero. Images of the R5 region (Buchon et al., 2013) were obtained

744 with a $63 \mathrm{X}$ objective and total number of $\mathrm{Arm}^{+} / \mathrm{Pros}^{-}$cells in a field were counted.

745 Quantifications of immunoblot were done with Image J. Student $t$-test and ANOVA were

746 used as statistical analysis and those were done with Prism (GraphPad) software.

747 Author Contributions: HS and YG designed the concept of the study. YG performed

748 all experiments. YG and HS jointly wrote the manuscript. 
749 Acknowledgments: We would like to thank all previous and current members of the

750 Steller Lab for their helpful suggestions and discussions, especially Adi Minis and Junko

751 Shimazu for critical reading of the ms. We also thank Drs. Norbert Perrimon, Jean-Paul

752 Vincent, Wei Du, Jessica Treisman, and Steven X. Hou for sharing their published

753 Drosophila lines, the Bloomington Stock Center and the Vienna Drosophila Research

754 Center for the fly stocks, and the Drosophila Genomics Resource Center and

755 Developmental Studies Hybridoma Bank (DSHB) for reagents. This work was

756 supported by NIH grant RO1GM60124 to H.S.

757 The authors declare no competing interests. 


\section{References}

759 Andreu P., Colnot, S., Godard, C., Gad, S., Chafey, P., Niwa-Kawakita, M., Laurent760 Puig, P., Kahn, A., Robine, S., Perret, C., Romagnolo, B. (2005). Crypt-restricted 761 proliferation and commitment to the Paneth cell lineage following Apc loss in the mouse 762 intestine. Development. 132(6):1443-51.

Bach, E.A., Ekas, L.A., Ayala-Camargo, A., Flaherty, M.S., Lee, H., Perrimon, N., and Baeg, G.H. (2007). GFP reporters detect the activation of the Drosophila JAK/STAT pathway in vivo. Gene Expr. Patterns 7, 323-331.

Bai P. (2012). Biology of Poly(ADP-Ribose) Polymerases: The Factotums of Cell Maintenance. Molecular Cell. 58-6; 947-958, 1.

Buchon, N., Osman, D., David, F.P.A., Yu Fang, H., Boquete, J.P., Deplancke, B., and Lemaitre, B. (2013). Morphological and Molecular Characterization of Adult Midgut Compartmentalization in Drosophila. Cell Rep. 3, 1725-1738.

Callow, M.G., Tran, H., Phu, L., Lau, T., Lee, J., Sandoval, W.N., Liu, P.S., Bheddah, S., Tao, J., Lill, J.R., et al. (2011). Ubiquitin ligase RNF146 regulates Tankyrase and Axin to promote Wnt signaling. PLoS One 6(7): e22595

Chiang, Y.J., Hsiao, S.J., Yver, D., Cushman, S.W., Tessarollo, L., Smith, S., and Hodes, R.J. (2008). Tankyrase 1 and Tankyrase 2 are essential but redundant for mouse embryonic development. PLoS One 3, e2639.

Cho-Park, P.F., and Steller, H. (2013). Proteasome regulation by ADP-ribosylation. Cell 153, 614-627.

Clevers, H., and Nusse, R. (2012). Wnt/B-catenin signaling and disease. Cell 149, 1192-1205.

Collins, R.T., and Treisman, J.E. (2000). Osa-containing Brahma chromatin remodeling complexes are required for the repression of Wingless target genes. Genes Dev. 14, 3140-3152.

Cordero, J.B., Stefanatos, R.K., Scopelliti, A., Vidal, M., and Sansom, O.J. (2012). Inducible progenitor-derived Wingless regulates adult midgut regeneration in Drosophila. EMBO J. 31, 3901-3917.

Croy, H.E., Fuller, C.N., Giannotti, J., Robinson, P., Foley, A.V.A., Yamulla, R.J., Cosgriff, S., Greaves, B.D., Von Kleeck, R.A., An, H.H., et al. (2016). The poly(ADPribose) polymerase enzyme Tankyrase antagonizes activity of the $\beta$-catenin destruction 801 
802 DaRosa, P.A., Wang, Z., Jiang, X., Pruneda, J.N., Cong, F., Klevit, R.E., and Xu, W. 803 (2014). Allosteric activation of the RNF146 ubiquitin ligase by a polyADP-ribosylation

804

805

806

807

808

809

810

811

812

813

814

815

816

817

818

819

820

821

822

823

824

825

826

827

828

829

830

831

832

833

834

835

836

837

838

839

840

841

842

843

844

845

846

847 signal. Nature. 8; 517(7533): 223.

Feng, Y., Li, X., Ray, L., Song, H., Qu, J., Lin, S., and Lin, X. (2014). The Drosophila Tankyrase regulates $\mathrm{Wg}$ signaling depending on the concentration of dAxin. Cell. Signal. 26, 1717-1724.

Feng, Y., Li, Z., Lv, L., Du, A., Lin, Z., Ye, X., Lin, Y., Lin, X. (2018) Tankyrase regulates apoptosis by activating JNK signaling in Drosophila. Biochem Biophys Res Commun. Sep 18;503(4):2234-2239. doi: 10.1016/j.bbrc.2018.06.143. Epub 2018 Jul 9.

Fevr, T., Robine, S., Louvard, D., and Huelsken, J. (2007). Wnt/ $\beta$-catenin is essential for intestinal homeostasis and maintenance of intestinal stem cells. Mol. Cell. Biol. 27, 7551-7559.

Gerlach, J.P., Emmink, B.L., Nojima, H., Kranenburg, O., and Maurice, M.M. (2014). Wnt signaling induces accumulation of phosphorylated $\beta$-catenin in two distinct cytosolic complexes. Open Biol. 4, 140120-140120.

Gibson, A.B., and Kraus, W.L. (2012). New insights into the molecular and cellular functions of poly-(ADP-ribose) and PARPs Nature Reviews Molecular Cell Biology 13; 411-424.

Ghiglione, C., Devergne, O., Georgenthum, E., Carballès, F., Médioni, C., Cerezo, D., Noselli, S. (2002). The Drosophila cytokine receptor Domeless controls border cell migration and epithelial polarization during oogenesis. Development 129, 5437-5447.

Gratz, S.J., Cummings, A.M., Nguyen, J.N., Hamm, D.C., Donohue, L.K., Harrison, M.M., Wildonger, J., and O'connor-Giles, K.M. (2013). Genome engineering of Drosophila with the CRISPR RNA-guided Cas9 nuclease. Genetics 194, 1029-1035.

Gratz, S.J., Ukken, F.P., Rubinstein, C.D., Thiede, G., Donohue, L.K., Cummings, A.M., and Oconnor-Giles, K.M. (2014). Highly specific and efficient CRISPR/Cas9-catalyzed homology-directed repair in Drosophila. Genetics 196, 961-971.

Hamada, F., Tomoyasu, Y., Takatsu, Y., Nakamura, M., Nagai, S.I., Suzuki, A., Fujita, F., Shibuya, H., Toyoshima, K., Ueno, N., et al. (1999). Negative regulation of Wingless signaling by D-Axin, a Drosophila homolog of Axin. Science. 283, 1739-1742.

Herr, P., Hausmann, G., Basler, K. (2012). WNT secretion and signaling in human disease. Trends Mol Med. (8):483-93.

Hsiao, S.J., Poitras, M.F., Cook, B.D., Liu, Y., and Smith, S. (2006). Tankyrase 2 poly(ADP-Ribose) polymerase domain-deleted mice exhibit growth defects but have normal telomere length and capping. Mol. Cell. Biol. 26, 2044-2054. 
Huang, S.M.A., Mishina, Y.M., Liu, S., Cheung, A., Stegmeier, F., Michaud, G.A., Charlat, O., Wiellette, E., Zhang, Y., Wiessner, S., et al. (2009). Tankyrase inhibition stabilizes Axin and antagonizes Wnt signaling. Nature 461, 614-620.

Jiang, H., Patel P.H., Kohlmaier, A., Grenley, M.O., McEwen, D.G., Edgar, B.A. (2009). Cytokine/Jak/Stat signaling mediates regeneration and homeostasis in the Drosophila midgut. Cell. Jun 26;137(7):1343-55. doi: 10.1016/j.cell.2009.05.014.

Kinzler, K., Nilbert, M., Su, L., Vogelstein, B., Bryan, T., Levy, D., Smith, K., Preisinger, A., Hedge, P., McKechnie, D., et al. (1991). Identification of FAP locus genes from chromosome 5q21. Science. 253, 661-665.

Korinek, V., Barker, N., Morin, P.J., van Wichen, D., de Weger, R., Kinzler, K.W., Vogelstein, B., and Clevers, H. (1997). Constitutive transcriptional activation by a betacatenin-Tcf complex in APC $^{-/-}$colon carcinoma. Science 275, 1784-1787.

Korinek, V., Barker, N., Moerer, P., Van Donselaar, E., Huls, G., Peters, P.J., and Clevers, H. (1998). Depletion of epithelial stem-cell compartments in the small intestine of mice lacking Tcf-4. Nat. Genet. 19, 379-383.

Kramps, T., Peter, O., Brunner, E., Nellen, D., Froesch, B., Chatterjee, S., Murone, M., Züllig, S., and Basler, K. (2002). Wnt/Wingless signaling requires BCL9/leglessmediated recruitment of pygopus to the nuclear $\beta$-catenin-TCF complex. Cell 109, 4760.

Lee, E., Salic, A., Krüger, R., Heinrich, R., and Kirschner, M.W. (2003). The roles of APC and Axin derived from experimental and theoretical analysis of the Wnt pathway. PLoS Biol. 1.

Li, V.S.W., Ng, S.S., Boersema, P.J., Low, T.Y., Karthaus, W.R., Gerlach, J.P., Mohammed, S., Heck, A.J.R., Maurice, M.M., Mahmoudi, T., et al. (2012). Wnt signaling through inhibition of $\beta$-catenin degradation in an intact Axin1 Complex. Cell 149, 12451256.

Lin, G., Xu, N., and Xi, R. (2008). Paracrine Wingless signaling controls self-renewal of Drosophila intestinal stem cells. Nature 455, 1119-1123.

Lu, J., Ma, Z., Hsieh, J.C., Fan, C.W., Chen, B., Longgood, J.C., Williams, N.S., Amatruda, J.F., Lum, L., and Chen, C. (2009). Structure-activity relationship studies of small-molecule inhibitors of Wnt response. Bioorganic Med. Chem. Lett. 19, 3825-3827.

Markstein, M., Dettorre, S., Cho, J., Neumuller, R.A., Craig-Muller, S., and Perrimon, N. (2014). Systematic screen of chemotherapeutics in Drosophila stem cell tumors. Proc. Natl. Acad. Sci. 111, 4530-4535. 
894

Mattila, J., Kokki, K., Hietakangas, V., Boutros, M. (2018) Stem Cell Intrinsic Hexosamine Metabolism Regulates Intestinal Adaptation to Nutrient Content. Dev Cell. Sep 7. pii: S1534-5807(18)30681-6. doi: 10.1016/j.devcel.2018.08.011.

Matsumoto, Y., La Rose, J., Lim, M., Adissu, H.A., Law, N., Mao, X., Cong, F., Mera, P., Karsenty, G., Goltzman, D., et al. (2017). Ubiquitin ligase RNF146 coordinates bone dynamics and energy metabolism. J. Clin. Invest. 127, 2612-2625.

Matsumoto, Y., Larose, J., Kent, O.A., Lim, M., Changoor, A., Zhang, L., Storozhuk, Y., Mao, X., Grynpas, M.D., Cong, F., et al. (2017). RANKL coordinates multiple osteoclastogenic pathways by regulating expression of ubiquitin ligase RNF146. J. Clin. Invest. 127, 1303-1315.

Micchelli, C.A., and Perrimon, N. (2006). Evidence that stem cells reside in the adult Drosophila midgut epithelium. Nature 439, 475-479.

Morin, P.J., Sparks, a B., Korinek, V., Barker, N., Clevers, H., Vogelstein, B., and Kinzler, K.W. (1997). Activation of beta-catenin-Tcf signaling in colon cancer by mutations in beta-catenin or APC. Science 275, 1787-1790.

Nishisho, I., Nakamura, Y., Miyoshi, Y., Miki, Y., Ando, H., Horii, A., Koyama, K., Utsunomiya, J., Baba, S., and Hedge, P. (1991). Mutations of chromosome $5 q 21$ genes in FAP and colorectal cancer patients. Science. 253, 665-669.

Nusse, R., and Clevers, H. (2017). Wnt/ $\beta$-catenin signaling, disease, and emerging therapeutic modalities. Cell 169, 985-999.

Ohlstein, B., and Spradling, A. (2006). The adult Drosophila posterior midgut is maintained by pluripotent stem cells. Nature 439, 470-474.

Port, F., Chen, H.-M., Lee, T., and Bullock, S.L. (2014). Optimized CRISPR/Cas tools for efficient germline and somatic genome engineering in Drosophila. Proc. Natl. Acad. Sci. 111, E2967-E2976.

Riffell J.L., Lord C.J, and Ashworth A. (2012). Tankyrase-targeted therapeutics: expanding opportunities in the PARP family. Nature Reviews Drug Discovery. 11; 923936.

Rubinfeld, B., Robbins, P., El-Gamil, M., Albert, I., Porfiri, E., and Polakis, P. (1997). Stabilization of beta-catenin by genetic defects in melanoma cell lines. Science 275 , 1790-1792.

Saito-Diaz, K., Benchabane, H., Tiwari, A., Tian, A., Li, B., Thompson, J.J., Hyde, A.S., Sawyer, L.M., Jodoin, J.N., Santos, E., et al. (2018). APC inhibits ligand-independent Wnt signaling by the clathrin endocytic pathway. Dev. Cell 44, 566-581.e8. 
Salic, A., Lee, E., Mayer, L., and Kirschner, M.W. (2000). Control of $\beta$-catenin stability: Reconstitution of the cytoplasmic steps of the Wnt pathway in Xenopus egg extracts. Mol. Cell 5, 523-532.

Theodosiou, N.A., and Xu, T. (1998). Use of FLP/FRT system to study Drosophila development. Methods A Companion to Methods Enzymol. 14, 355-365.

Tian, A., Benchabane, H., Wang, Z., and Ahmed, Y. (2016). Regulation of stem cell proliferation and cell fate specification by Wingless/Wnt signaling gradients enriched at adult intestinal compartment boundaries. PLoS Genet. 12.

Wang, Z., Tian, A., Benchabane, H., Tacchelly-Benites, O., Yang, E., Nojima, H., and Ahmed, Y. (2016a). The ADP-ribose polymerase Tankyrase regulates adult intestinal stem cell proliferation during homeostasis in Drosophila. Development 143, 1710-1720.

Wang, Z., Tacchelly-Benites, O., Yang, E., Thorne, C.A., Nojima, H., Lee, E., and Ahmed, Y. (2016b). Wnt/wingless pathway activation is promoted by a critical threshold of Axin maintained by the tumor suppressor APC and the ADP-ribose polymerase Tankyrase. Genetics 203, 269-281.

Xu, N., Wang, S.Q., Tan, D., Gao, Y., Lin, G., and Xi, R. (2011). EGFR, Wingless and JAK/STAT signaling cooperatively maintain Drosophila intestinal stem cells. Dev. Biol. 354, 31-43.

Yang, E., Tacchelly-Benites, O., Wang, Z., Randall, M.P., Tian, A., Benchabane, H., Freemantle, S., Pikielny, C., Tolwinski, N.S., Lee, E., et al. (2016). Wnt pathway activation by ADP-ribosylation. Nat. Commun. 7.

Zeidler, M.P., Bach, E.A., and Perrimon, N. (2000). The roles of the Drosophila JAK/STAT pathway. Oncogene 19, 2598-2606.

Zhang, Y., Liu, S., Mickanin, C., Feng, Y., Charlat, O., Michaud, G.A., Schirle, M., Shi, X., Hild, M., Bauer, A., et al. (2011). RNF146 is a poly-(ADP-ribose)-directed E3 ligase that regulates Axin degradation and Wnt signaling. Nat. Cell Biol. 13, 623-629.

Zhou, F., Rasmussen, A., Lee, S., and Agaisse, H. (2013). The UPD3 cytokine couples environmental challenge and intestinal stem cell division through modulation of JAK/STAT signaling in the stem cell microenvironment. Dev. Biol. 373, 383-393.

Zoranovic, T., Grmai, L., and Bach, E. (2013). Regulation of proliferation, cell competition, and cellular growth by the Drosophila JAK-STAT pathway. Jak-Stat 2, e25408. 
bioRxiv preprint doi: https://doi.org/10.1101/296830; this version posted January 15,2019 . The copyright holder for this preprint (which was not certified py peer review) is the author/funder, who has granted bioRxiv a license to display the preprint in perpetuity. It is made available under Figure 1

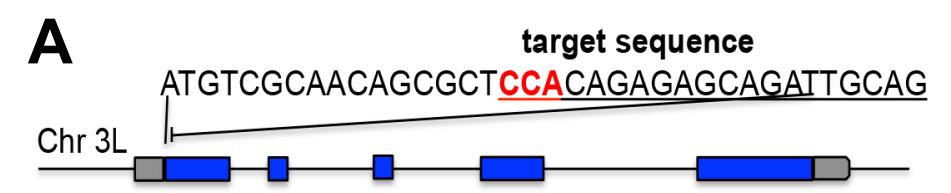

\section{Iduna genomic locus}

WT ATGTCGCAACAGCGCTCCACAGAGCAGATTGCAG Mutant\#17 ATGTCGCAACAGCGCTCCACAG-----GATTGCAG Mutant\#78 ATGTCGCAACAGCGCTCCACAG-----CAGATTGCAG

C

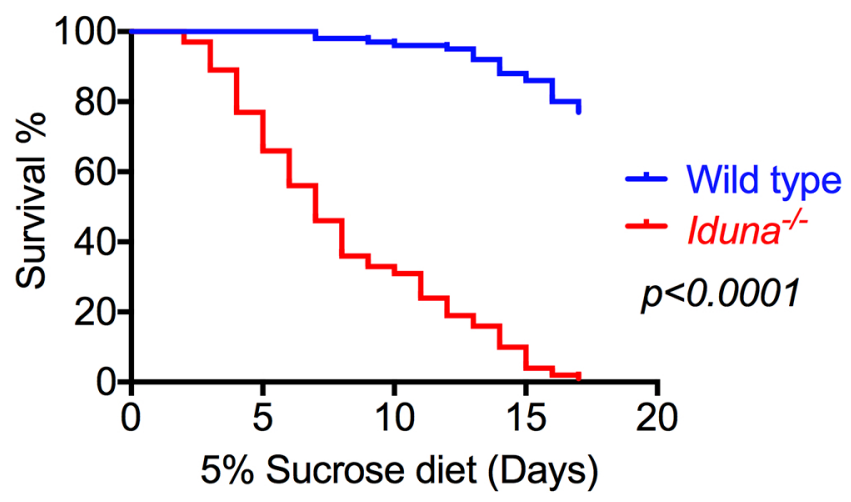

Deletion size(nt)

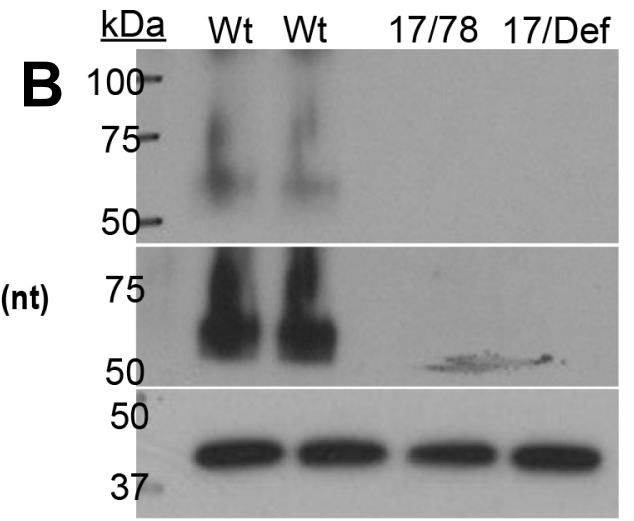

Iduna

(short exposure)

WB: $\alpha$-dlduna

Iduna

(long exposure)

$\beta$-actin 
bioRxiv preprint doi: https://doi.org/10.1101/296830; this version posted January 15, 2019. The copyright holder for this preprint (which was not

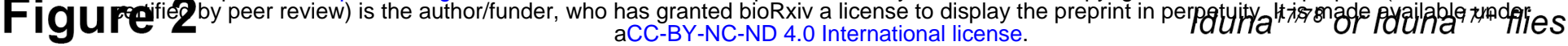

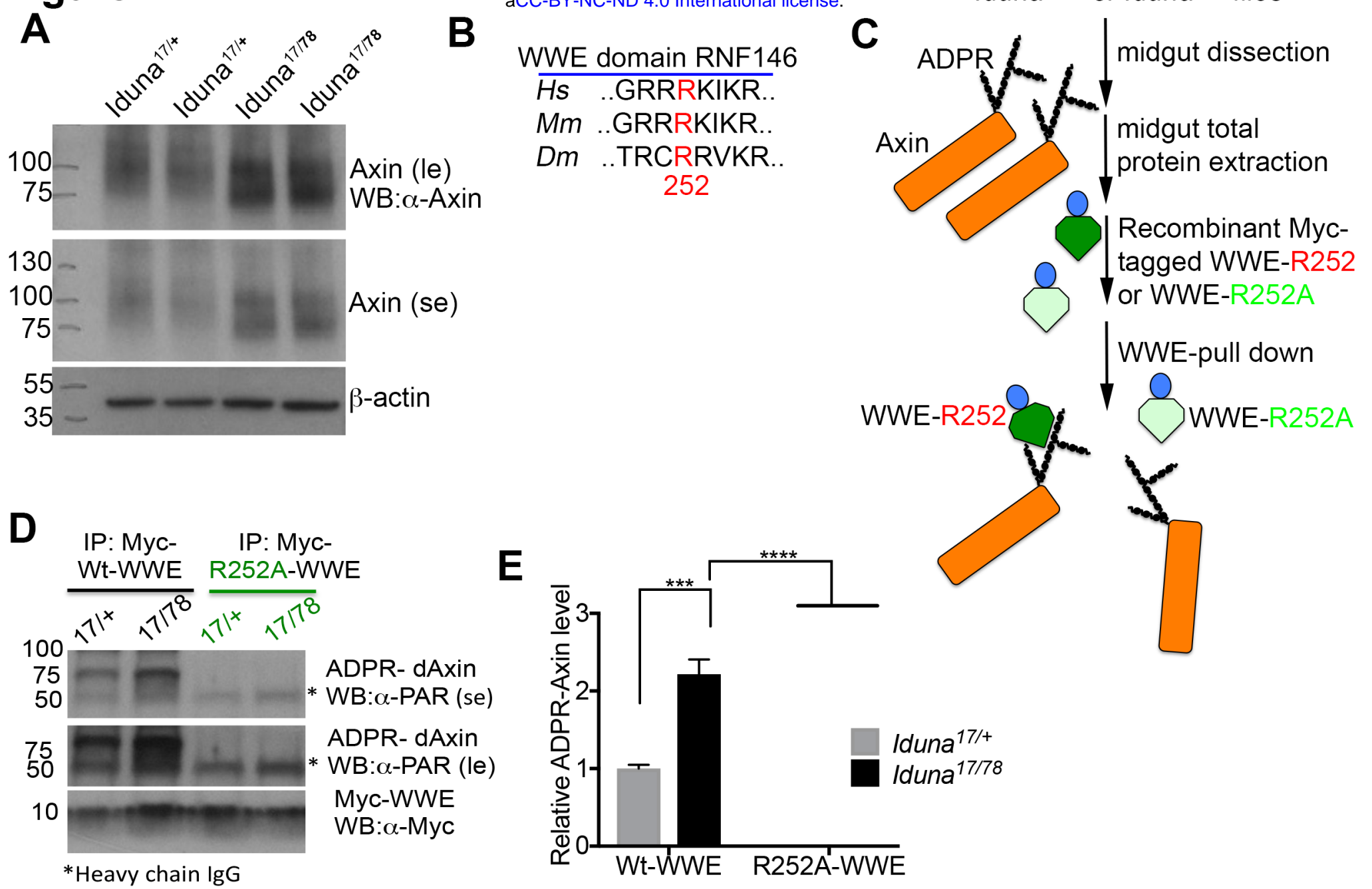

*Heavy chain lgG

WWE domain RNF146

..GRRRKIKR

.

ADPR

midgut tota

protein extraction

Recombinant Myc-

tagged WWE-R252

WWE-R252A

WWE-pull down

IP: Myc- Myc-

Wt-WWE R252A-WWE

WB: $\alpha-P A R$ (le)

Myc-WWE

WB: $\alpha-M y c$

Wt-WWE R252A-WWE 
bioRxiv preprint doi: https://doi.org/10.1101/296830; this version posted January 15,2019 . The copyright holder for this preprint (which was not
FIg UTE
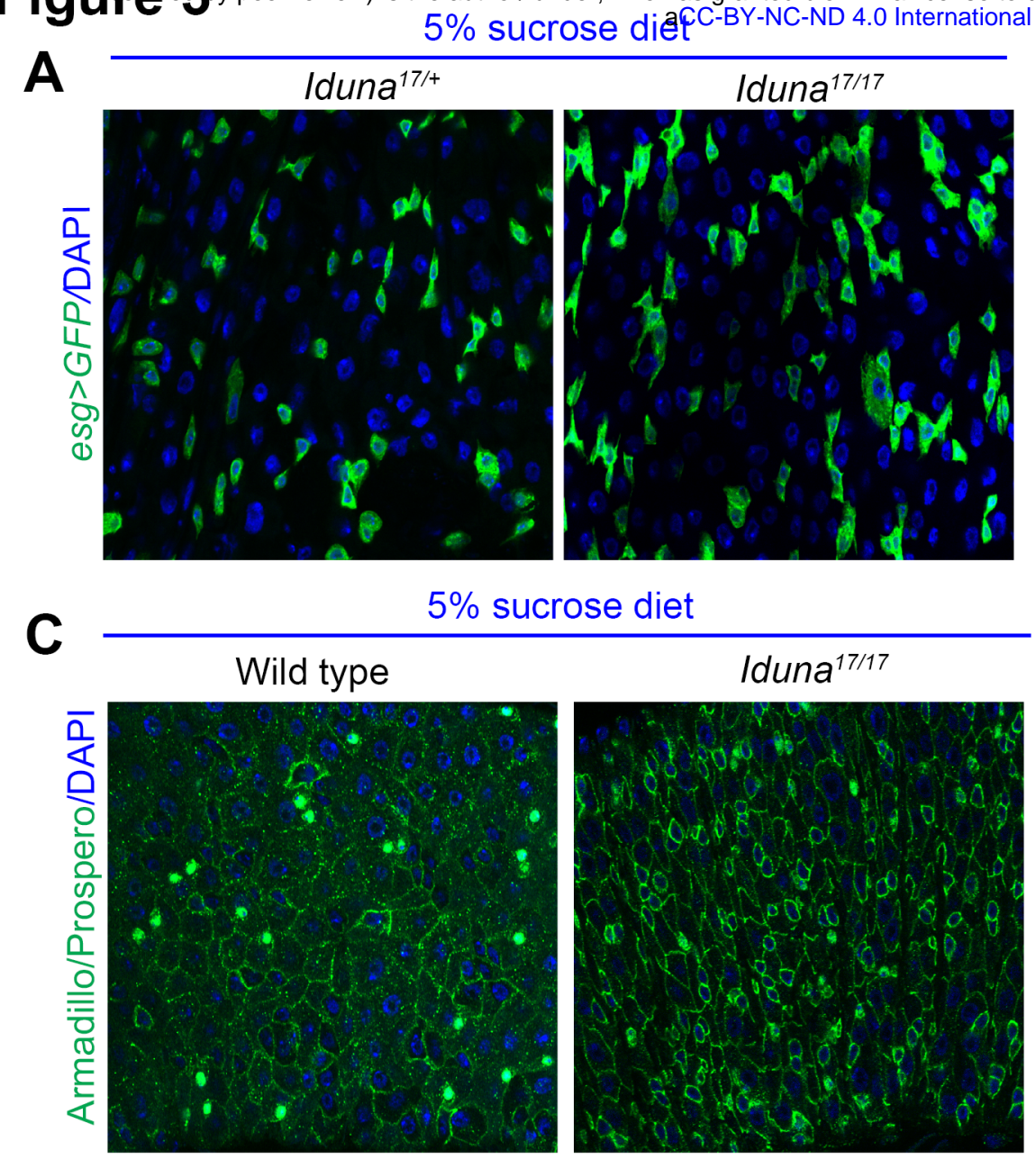

B

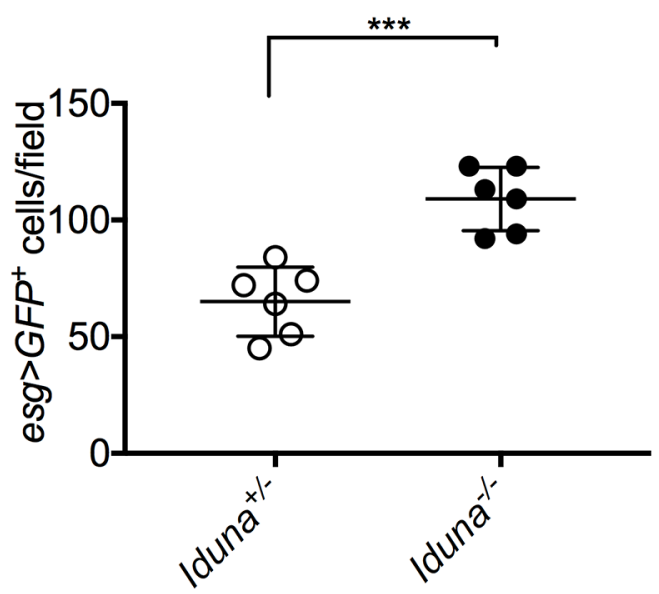

esg $>G F P^{+}$cells upon nutrient deprivation
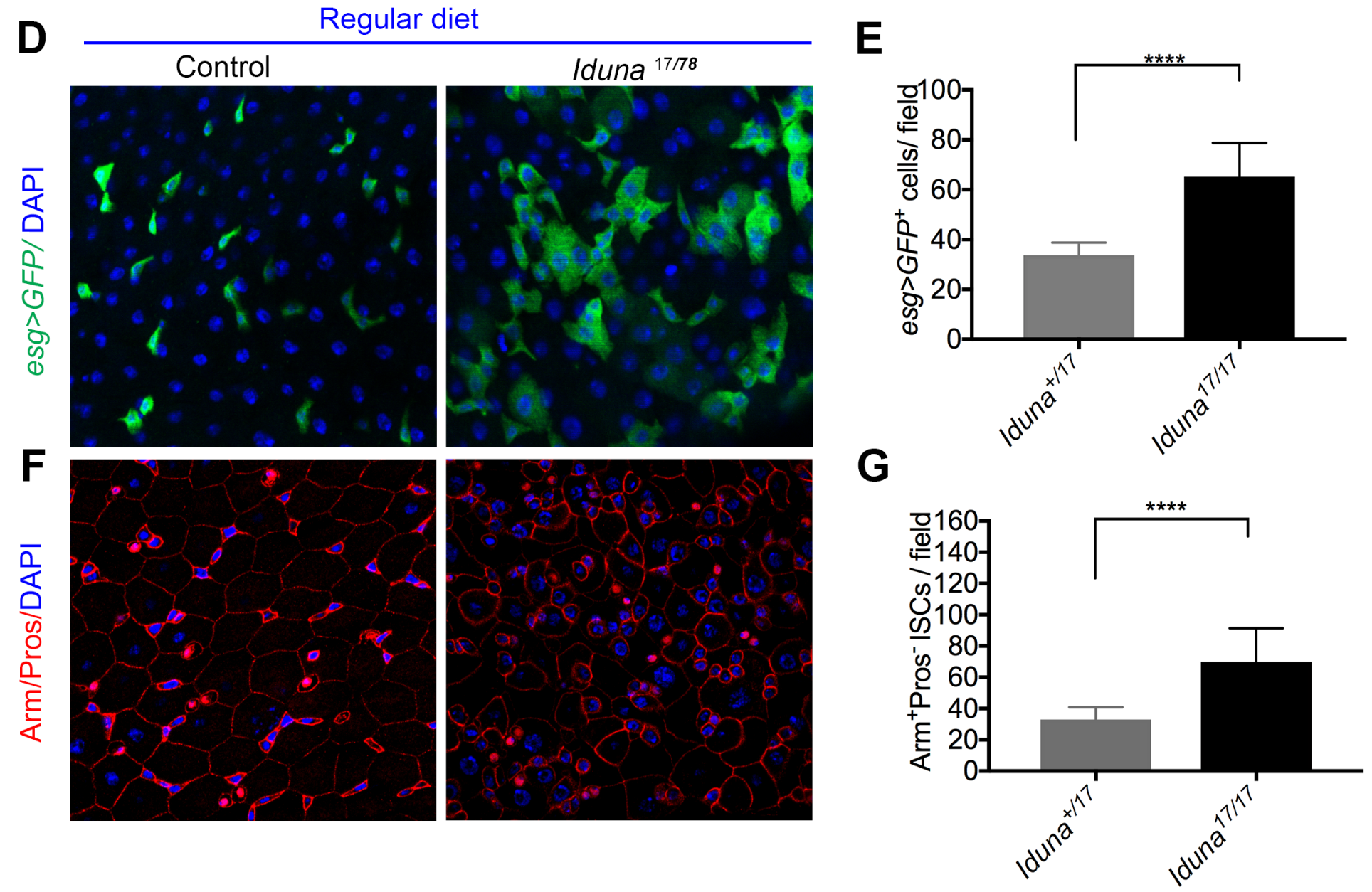
bioRxiv preprint doi: https://doi.org/10.1101/296830; this version posted January 15,2019 . The copyright holder for this preprint (which was not certified by peer review) is the author/funder, who has granted bioRxiv a license to display the preprint in perpetuity. It is made available under

Figure 4

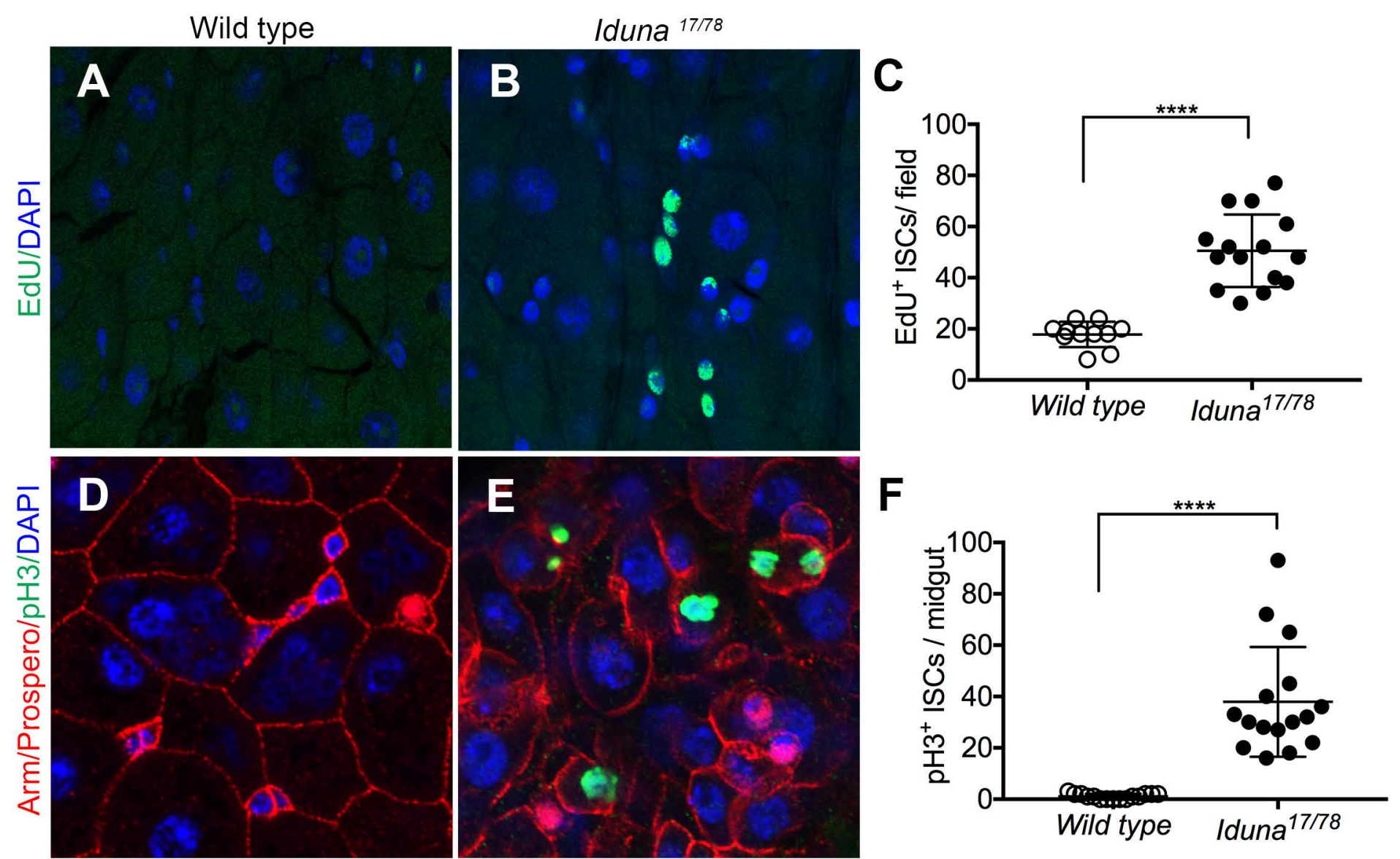


bioRxiv preprint doi: https://doi.org/10.1101/296830; this version posted January 15,2019 . The copyright holder for this preprint (which was not FIO 1 Pe

A

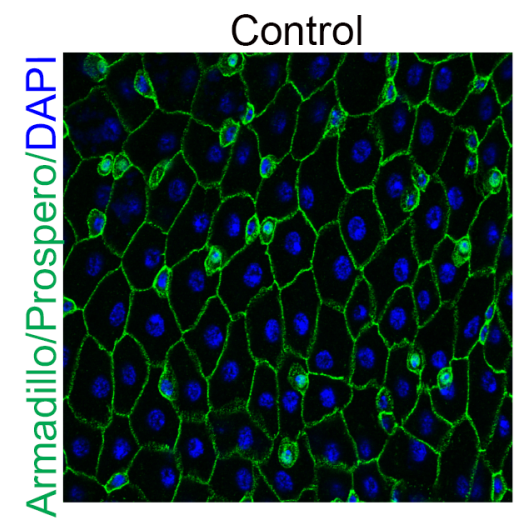

B

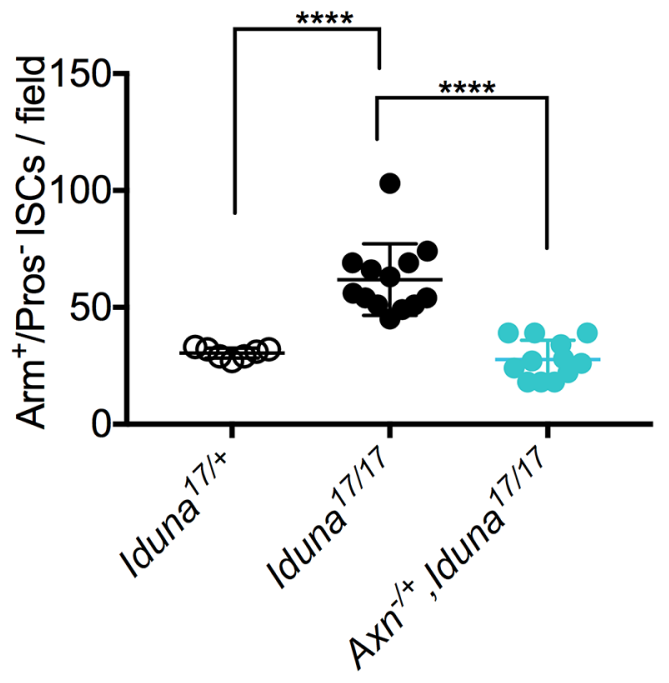

D

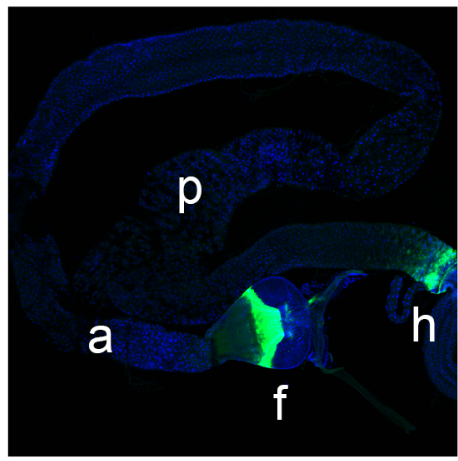

Drosophila midgut
Iduna ${ }^{17 / 17}$
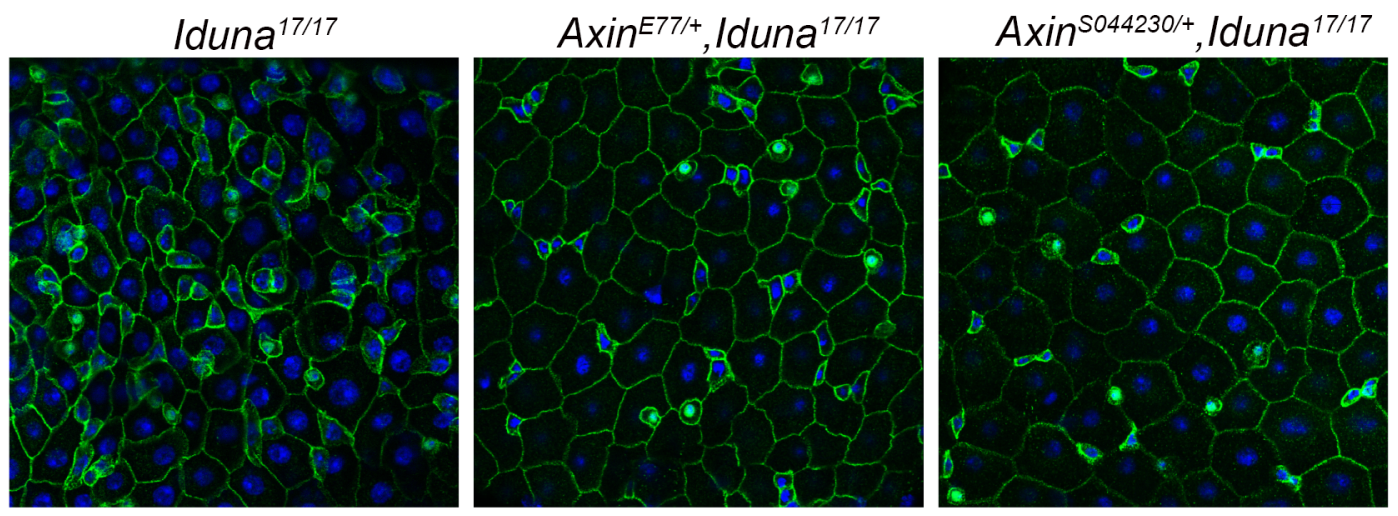

C

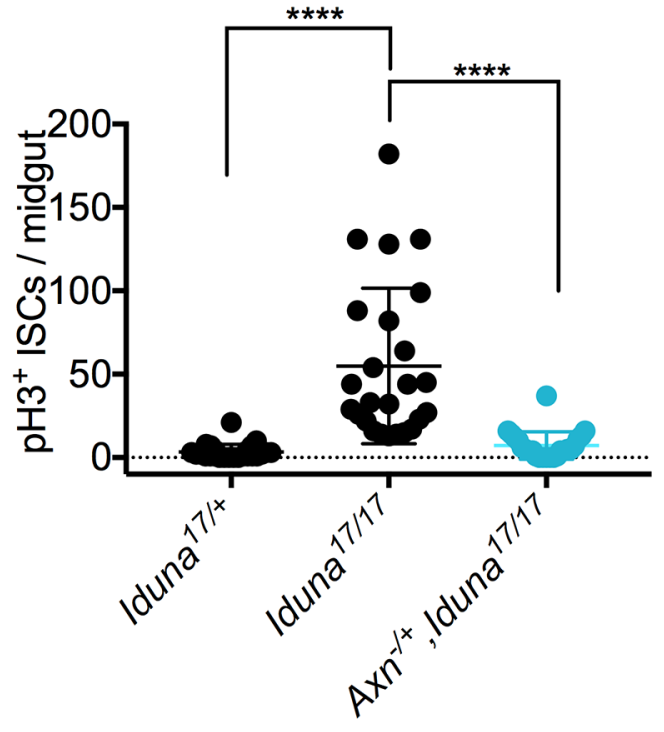

E

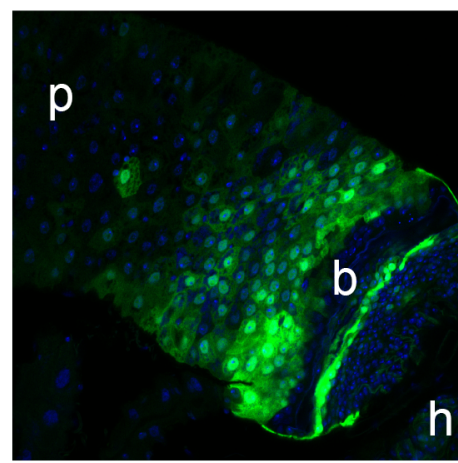

posterior midgut

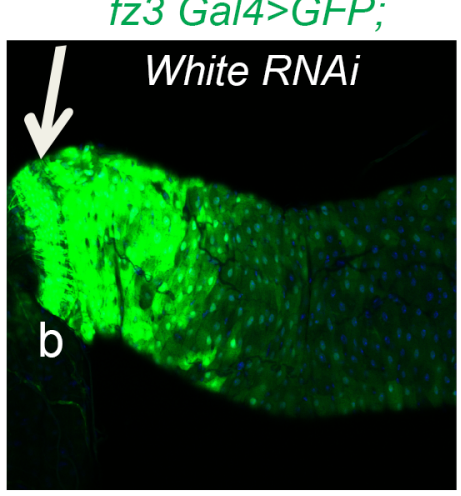

fz3 Gal4>GFP;

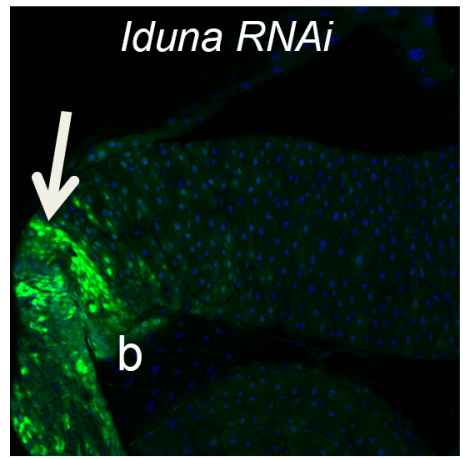

posterior midgut 
Figure 6

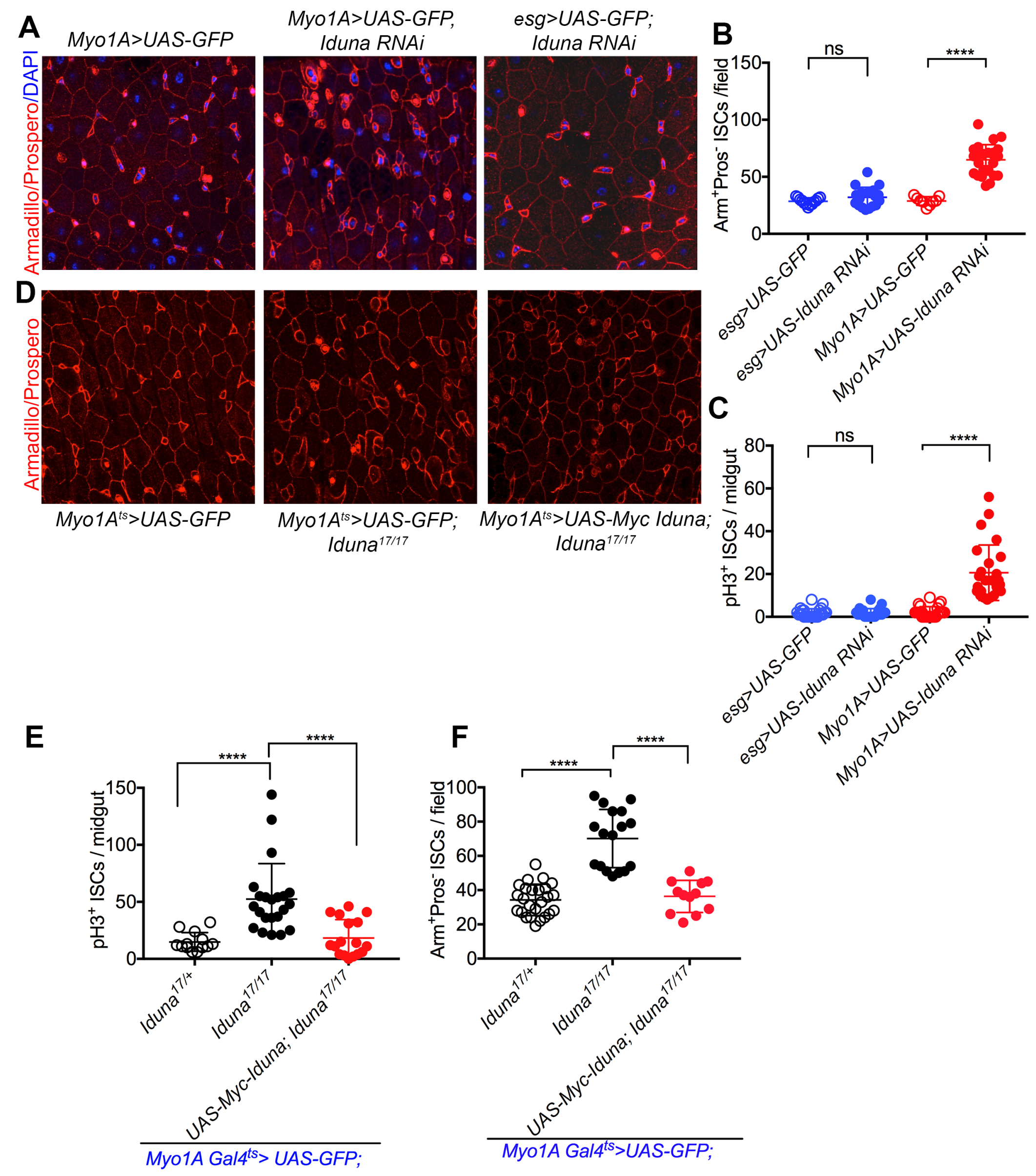




\section{Supplementary Figure Legends}

2 Figure S1: Iduna inactivation does not cause developmental defects in

3 Drosophila. A- Identification of Iduna ${ }^{17}$ and Iduna ${ }^{78}$ mutant alleles. Iduna ${ }^{17}$ had

4 no detectable Iduna transcripts, and Iduna ${ }^{78}$ had severely reduced Iduna mRNA

5 based on RT-PCR. 7 day-old adult females were analyzed for expressions of

6 Iduna, Ribosomal protein 49 (a house keeping gene) and Ornitate

7 aminotransferase. B- Iduna mutants did not have defects in hatching their eggs.

$8 \mathrm{n}>250$ for each genotype. C- Iduna transheterozygous mutants did not have

9 defects in hatching their eggs. n>100 for each genotype. D- Iduna mutants do not

10 have nutrient uptake Iduna mutant larvae could be pupated and enclosed to adult

11 Drosophila. $\mathrm{n}>100$ for each genotype. E- There is no decrease in food intake in

12 Iduna mutant when flies kept under the regular diet. Quantification of adult fly

13 nutrient uptake by a calorimetric assay from regular dietary condition in Iduna

14 mutants and Oregon R.

15 Figure S2: Iduna depletion leads to increased Axin and Tankyrase protein

16 levels. A- Mis-expression of GFP-Axin in adult eyes did not result in obvious eye

17 phenotype. Five day-old adult male eyes were imaged. B- Mis-expressed

18 Tankyrase however led to rough eye. Iduna inactivation promotes the eye

19 phenotype. Five day-old adult male eyes were imaged. C- Iduna inactivation

20 leads to mis-expressed GFP-Axin elevation. A UAS-GFP-Axin reporter transgene

21 was expressed under GMR driver in the Iduna mutants or wild type. D- Iduna

22 mutants had 2.5-fold increased GFP-Axin protein. Quantification of mis-

23 expressed GFP-Axin immunoblottings. Results are based on two repeats of 
24 independent replicates and Axin protein levels were normalized to $\beta$-actin. E-

25 Flag- tagged mis-expressed TNKS protein accumulates in Iduna mutants. A

26 UAS-Flag-TNKS reporter transgene was expressed under the GMR-Gal4 driver

27 in Iduna mutants or wild type. F- Iduna mutants had 3.5-fold increased levels of

28 flag-tagged TNKS. Quantification of Flag-TNKS immunoblottings. Five day-old

29 adult male heads were dissected and $20 \mu \mathrm{g}$ of total protein lysates were analyzed

30 by immunoblotting to assess the levels of GFP-Axin or Flag-tagged TNKS using

$31 \alpha$-GFP or $\alpha$-flag antibodies, respectively. Western blot quantification was

32 performed based on two independent experimental replicates, and protein levels

33 were normalized with $\beta$-actin. Oregon $\mathrm{R}$ flies were used as a wild type control.

34 Flies were fed with regular diet at $24-25^{\circ} \mathrm{C}$.

35 Figure S3: Iduna inactivation causes increased mis-expressed Axin protein

36 levels in the midgut.

37 A- Iduna mutant midguts had elevated mis-expressed GFP-Axin protein. Midguts

38 of 7 day-old adult females, which were expressing GFP-Axin under the

39 temperature sensitive Myo1A-Gal4 driver, were dissected, lysed and analyzed by

40 GFP immunoblotting. Iduna mutants had more Axin protein compared to the wild

41 type. $20 \mu \mathrm{g}$ total intestinal lysates were analyzed by GFP immunoblotting and $\alpha$ -

42 tubulin was used as a loading control. B- Loss-of-Iduna resulted in 2.2-fold GFP-

43 Axin accumulation in the midgut. Western blot quantification was performed

44 based on two independent experimental replicates, and protein levels were

45 normalized to $\alpha$-tubulin. C- Iduna mutant clones have elevated mis-expressed

46 GFP-Axin compared to their WT neighbours. A UAS-GFP-Axin transgene was 
47 expressed under the temperature sensitive Myo1A-Gal4 driver in the FRT80B-

48 Iduna ${ }^{17}$ mutant. Midgut mutant clones were induced during larval development by

49 daily incubation at $37^{\circ} \mathrm{C}$ for $1 \mathrm{~h}$. Adult female FRT80B-NIs-Red/FRT80B-Iduna ${ }^{17}$

50 flies were collected after eclosion, incubated at $29^{\circ} \mathrm{C}$ and analyzed on day 7.

51 Unlabeled cells represent Iduna mutant clones, whereas cells stained for nuclear

52 RFP are either wild type or Iduna heterozygous. $p<0.001$ is indicated as *** and $53 p<0.0001$ was marked as ****.

54 Figure S4: Iduna is not required for differentiation of ISC. A- Intestinal stem

55 cells in the Drosophila midgut give rise to enterocytes and enteroendocrine cells.

56 ISCs give rise to two different types of daughter progenitors, undifferentiated

57 enteroblasts (EBs) and pre-enteroendocrine cells (Pre-EE). EBs and pre-EEs

58 differentiate into enterocytes (ECs) and enteroendocrine (EEs) cells,

59 respectively. B- ISCs and ECs can be distinguished by their cell sizes, high level

60 of membrane-associated Armadillo, and lack of nuclear Prospero. On the other

61 hand, differentiated EEs are small and can be identified by nuclear Prospero

62 staining. Finally, small-sized ISCs are stained with Armadillo but not with nuclear

63 Prospero. In the image, small ISCs were co-stained with escargot (green), and

64 Armadillo (red). On the other hand, small EEs were shown with the red arrow and

65 stained with Armadillo (red) and nuclear Prospero (red). Bigger cells are

66 enterocytes whose cell membrane is stained with Armadillo (red). DAPI staining

67 in blue marks the cell nucleus. Flies were fed with regular diet at $24-25^{\circ} \mathrm{C} . / d u n a$

68 mutants contain slightly more cells in their midgut. It appears that an increase in

69 ISC number is responsible for this effect. C-E- No differences in the numbers of 
70 enterocytes and enteroendocrine cells were observed in Iduna mutants. F- Iduna

71 is not required for the differentiation of stem cells into enterocytes. Enterocytes

72 were marked with GFP expressed under the control of enterocyte specific driver,

73 Myo1A-Gal4. 7d- old mutant clones were analyzed. Control cells are shown with

74 nuclear RFP, and Iduna mutant clones are marked with a white line. G- Genetic

75 depletion of Iduna did not affect the differentiation of ISCs into enteroendocrine

76 cells. Mutant clones in $7 d$-old adult midguts were analyzed with Prospero

77 staining. Small nuclear Prospero-positive EE cells are labeled with yellow arrows

78 in Iduna mutant clones. Control cells are labeled with nuclear RFP, and mutant

79 clones are marked with a white line. Flies were fed with regular diet at $24-25^{\circ} \mathrm{C}$.

80 Figure S5: RNAi-mediated Iduna depletion in enterocytes does not cause

81 mortality upon nutrient deprivation. A- Three different Iduna RNAi lines were

82 expressed under the Myo1A driver. White RNAi was used as a control. B- There

83 was no significant change on the mean lifespan between white and Iduna RNAi

84 expressing flies. $\mathrm{n}=60$ for each genotype. C- Iduna inactivation in enteroblast

85 does not lead to increased lethality upon $5 \%$ sucrose diet at $28^{\circ} \mathrm{C} . \mathrm{n}=70$ for each

86 genotype. D- Ectopic expression of Iduna under Myo1A driver in enterocytes

87 does not rescue elevated mortality of Iduna mutants under reduced nutrient diet.

88 Two-day old mutant or wild type female flies were collected and kept on $5 \%$

89 sucrose diet at $28^{\circ} \mathrm{C}$ for the experiment in A-D. E- Enterocyte specific ectopic

90 expression of Iduna rescues the hyper-proliferation of midgut stem cells upon

91 nutrient deprivation. 2 day-old females were collected at $24-25^{\circ} \mathrm{C}$ and their 
92 regular diet was replaced with $5 \%$ sucrose diet at $28^{\circ} \mathrm{C}$. 9 day-old female flies

93 were examined with $\alpha$-Armadillo and Prospero antibodies.

94 Figure S6: Under regular physiological conditions, the Stat-GFP reporter is

95 mainly expressed in midgut stem cells and enteroblasts . A- 10x Stat-GFP

96 reporter was mainly positive in small sized cell populations but Prospero stained

97 enteroendocrine cells were negative for Stat-GFP in the midguts. B- Delta-lacZ

98 positive but Prospero negative cells were mainly positive for Stat-GFP

99 expression. It was also indicated with the white arrows that a small population of

100 cells, which were small-sized and GFP positive but Delta-lacZ negative. Those

101 could be undifferentiated progenitors like enteroblast cells. C- Armadillo positive

102 Prospero negative small sized stem and progenitor cells have Stat-GFP reporter

103 activity. 5 day-old female flies were dissected and stained with $\alpha$-Armadillo and

104 Prospero antibodies.

105 Figure S7: Iduna mutants have increased numbers of Stat-GFP positive 106 cells.

107 A- Iduna mutant clones had elevated Stat-GFP signaling in ISCs. 10X-Stat-GFP 108 is a reporter for STAT signaling activity. Iduna mutant clones displayed strongly

109 increased staining of this reporter. 7 day-old females were dissected and the 110 posterior midguts were analyzed. B- Quantification of Stat-GFP reporter

111 expression in Iduna mutant clones. GFP intensity was measured with Image $\mathrm{J}$

112 and normalized with control cells. Iduna mutant clones showed 4-5 fold higher

113 reporter expression. C- E- Iduna mutants have more Stat-GFP positive stem cells

114 and progenitors in the midguts. 7 day-old females were dissected and the 
115 posterior midguts were analyzed by confocal microscopy. $n>6$ for each genotype.

$116 p<0.0001$ is indicated as ${ }^{* * *}$. F- Delta protein is elevated in the midguts of Iduna

117 mutants. 7 day-old females were dissected and the midguts were stained for

118 Delta. Flies were collected and kept on regular diet at $24-25^{\circ} \mathrm{C}$.

120 Figure S8: RNAi-mediated Iduna depletion increases Upd3>GFP reporter

121 activity. A- Knock-down of Iduna results in upregulation of Upd3. Iduna was

122 down-regulated by two different UAS-RNAi lines (\#36029 and \#40882) under

123 Upd3-Gal4 driver. Upd3>GFP was used as a reporter for Upd3 gene expression.

124 White RNAi served as control. B-C- Upd3 was upregulated in the enterocytes.

125 Dissected midguts were stained with $\alpha$-Armadillo and Prospero antibodies. ECs

126 were Upd3>GFP expressing cells but EEs and ISCs not. 3 day-old female flies

127 were dissected and their posterior midguts were analyzed by confocal

128 microscopy. 
bioRxiv preprint doi: https://doi.org/10.1101/296830; this version posted January 15,2019 . The copyright holder for this preprint (which was not

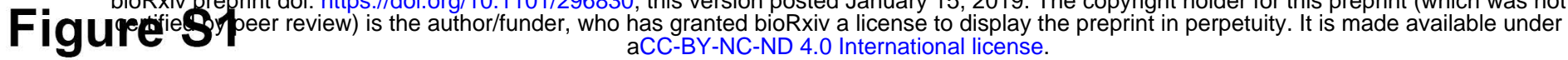

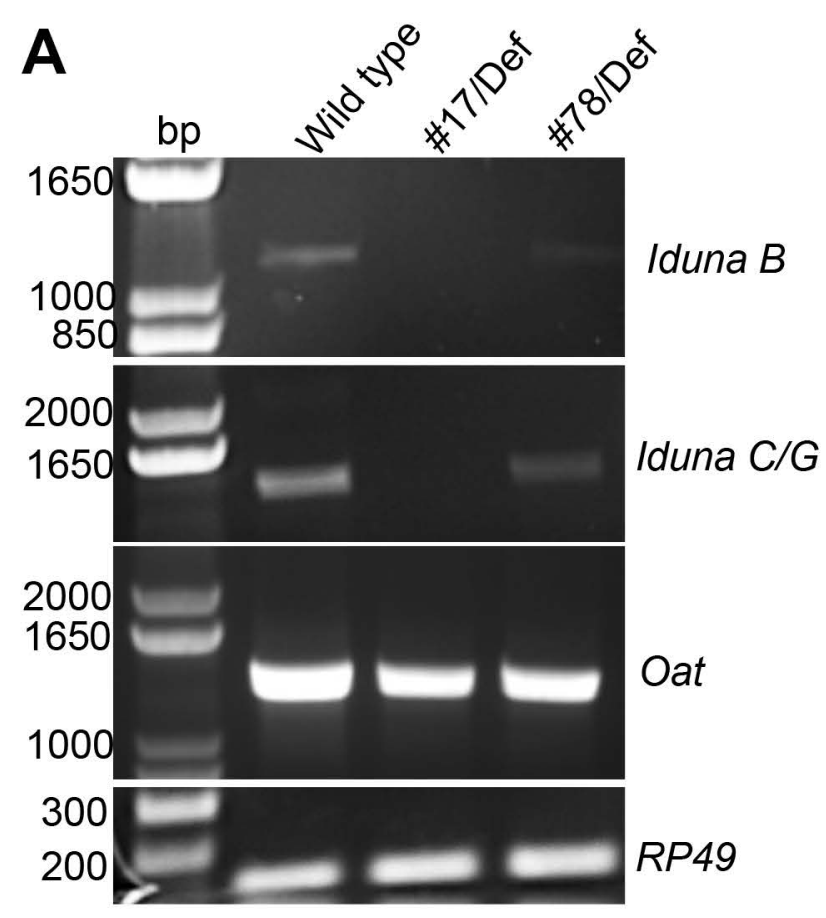

D
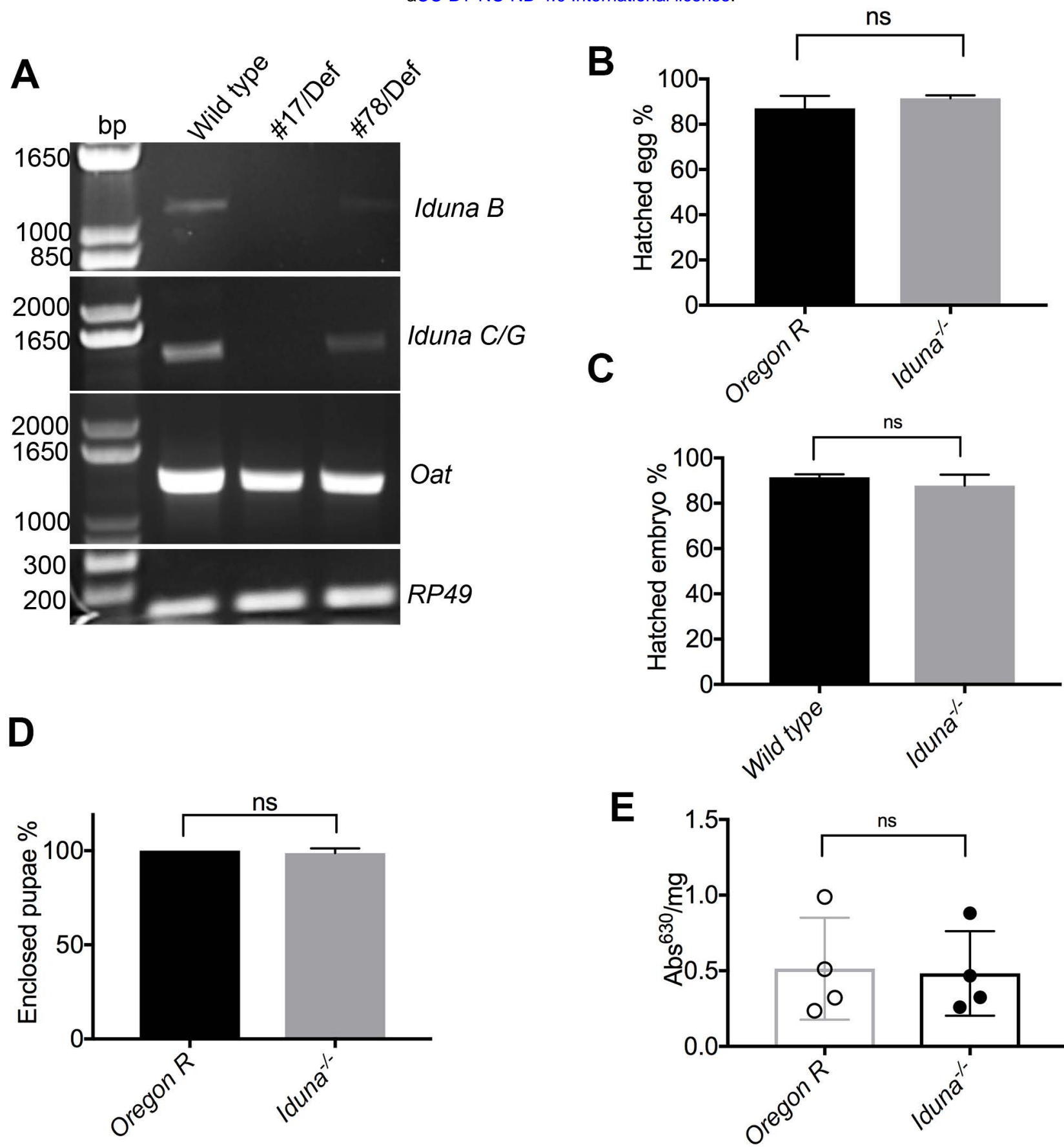

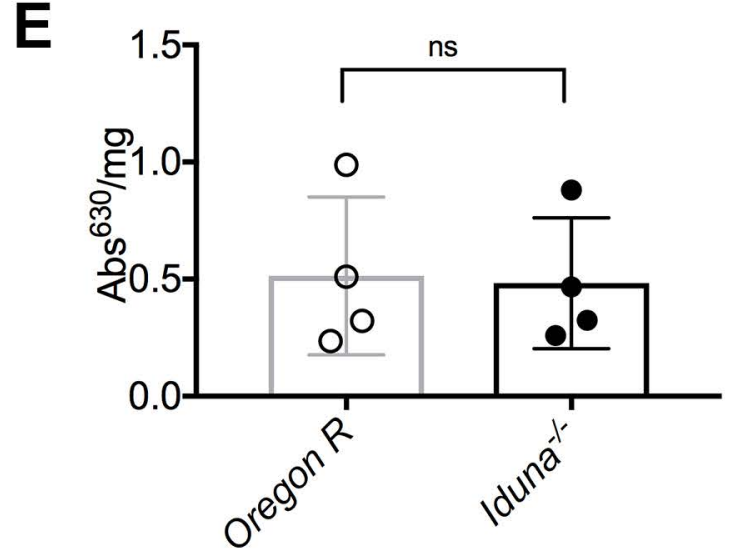

Adult fly nutrient uptake 
bioRxiv preprint doi: https://doi.org/10.1101/296830; this version posted January 15,2019 . The copyright holder for this preprint (which was not certified by peer review) is the author/funder, who has granted bioRxiv a license to display the preprint in perpetuity. It is made available under Figure S2 aCC-BY-NC-ND 4.0 International license.

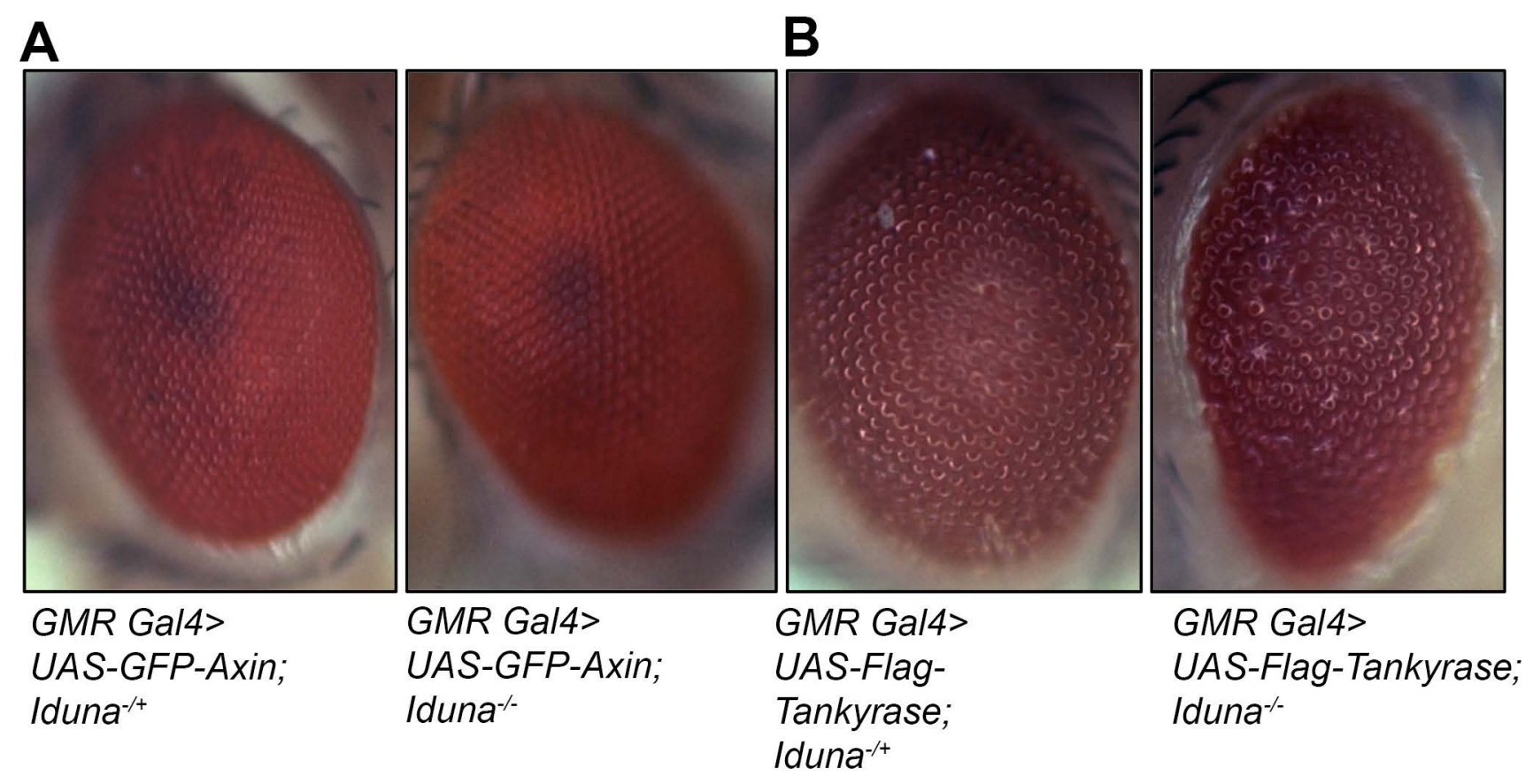

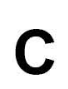

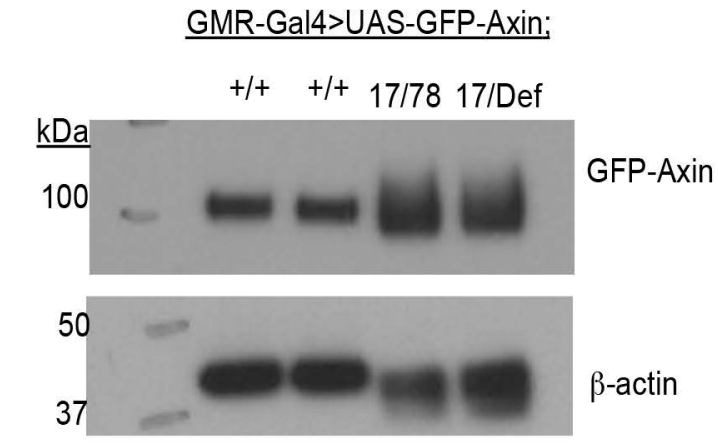

$\mathbf{E}$

GMR-Gal4 >UAS- Flag-Tankyrase:

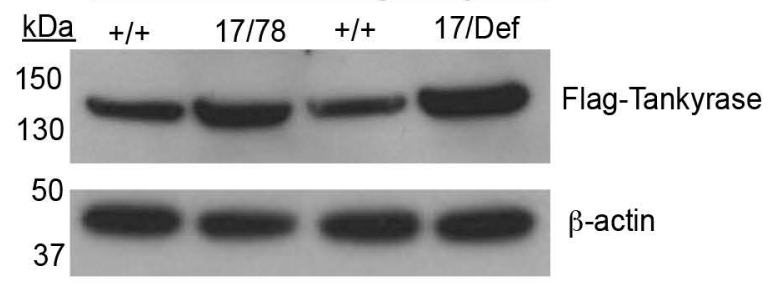

D

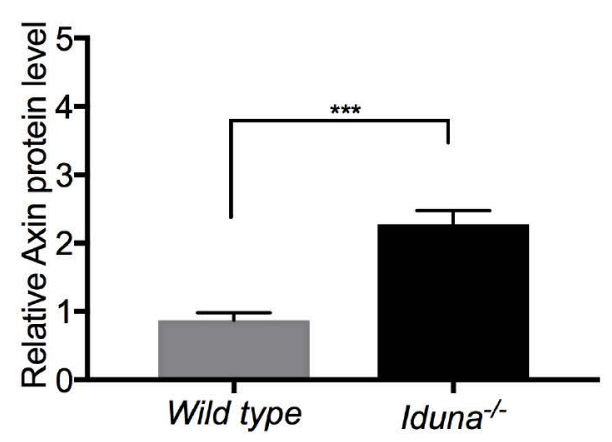

$\mathbf{F}$

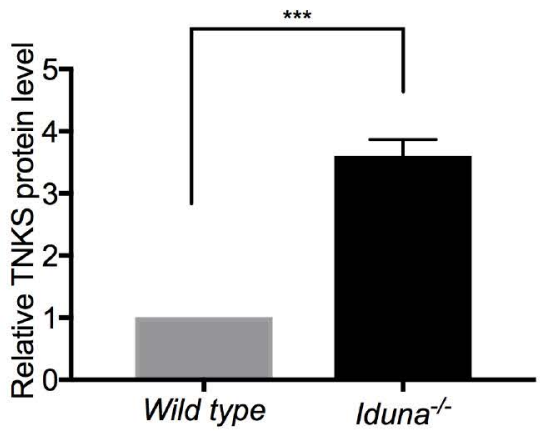


bioRxiv preprint doi: https://doi.org/10.1101/296830; this version posted January 15,2019 . The copyright holder for this preprint (which was not

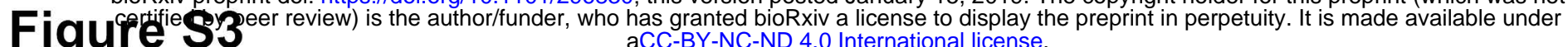

A

Myo1Ats $>$ UAS-GFP-Axin:

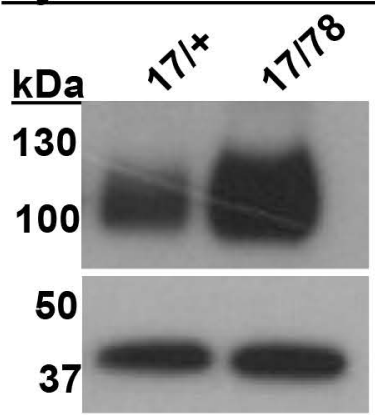

B

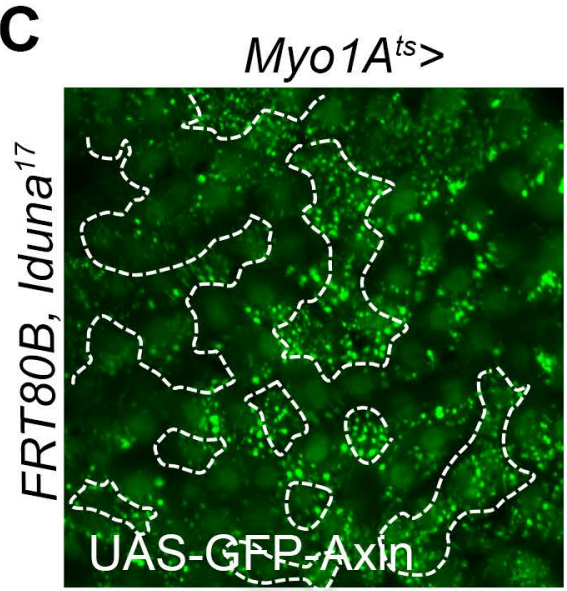
aCC-BY-NC-ND 4.0 International license.
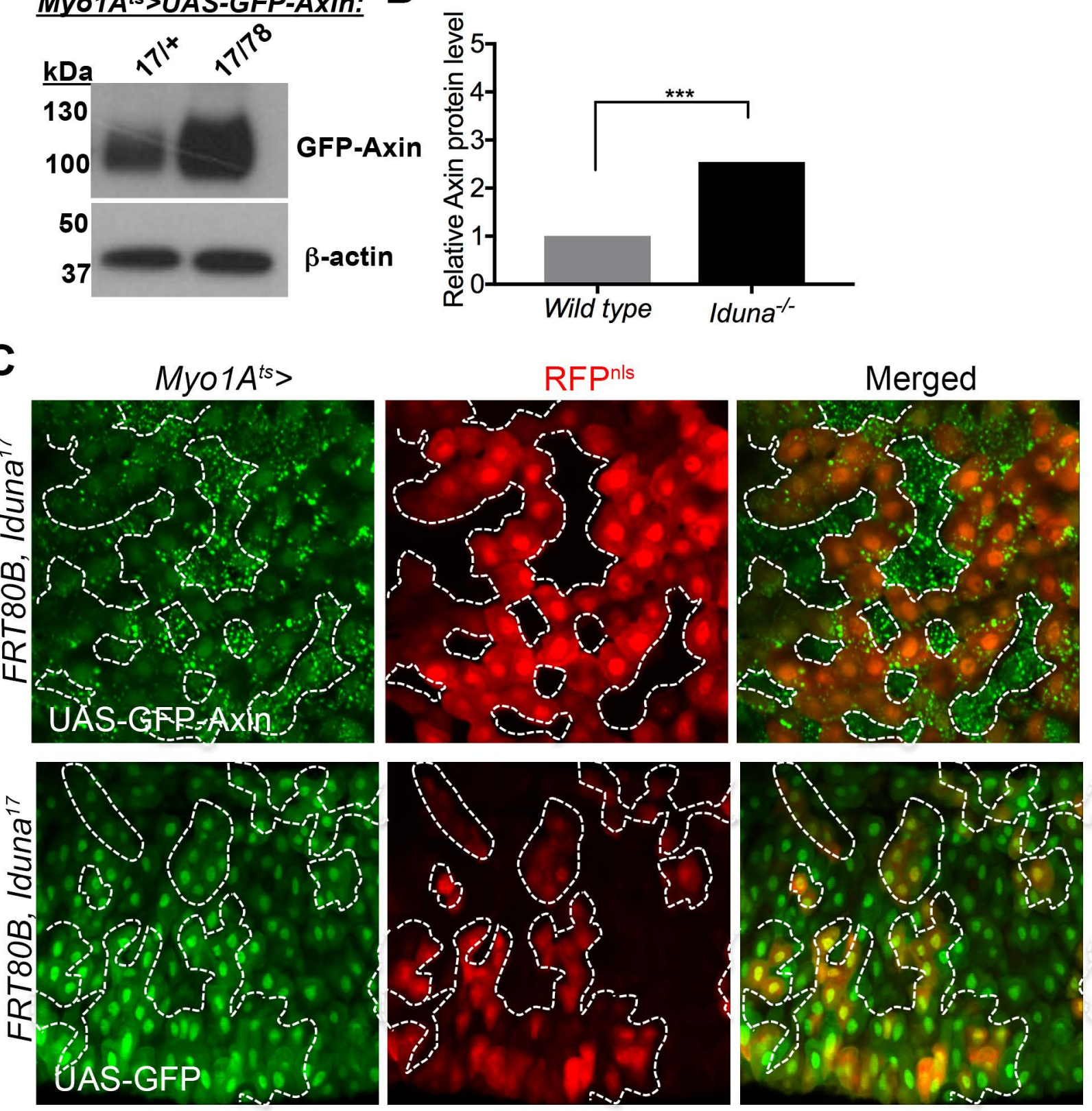
bioRxiv preprint doi: https://doi.org/10.1101/296830; this version posted January 15,2019 . The copyright holder for this preprint (which was not

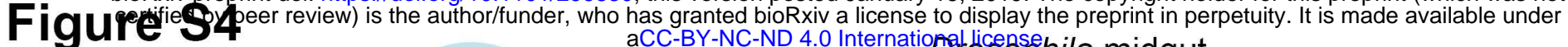

A

Enterocyte

EC

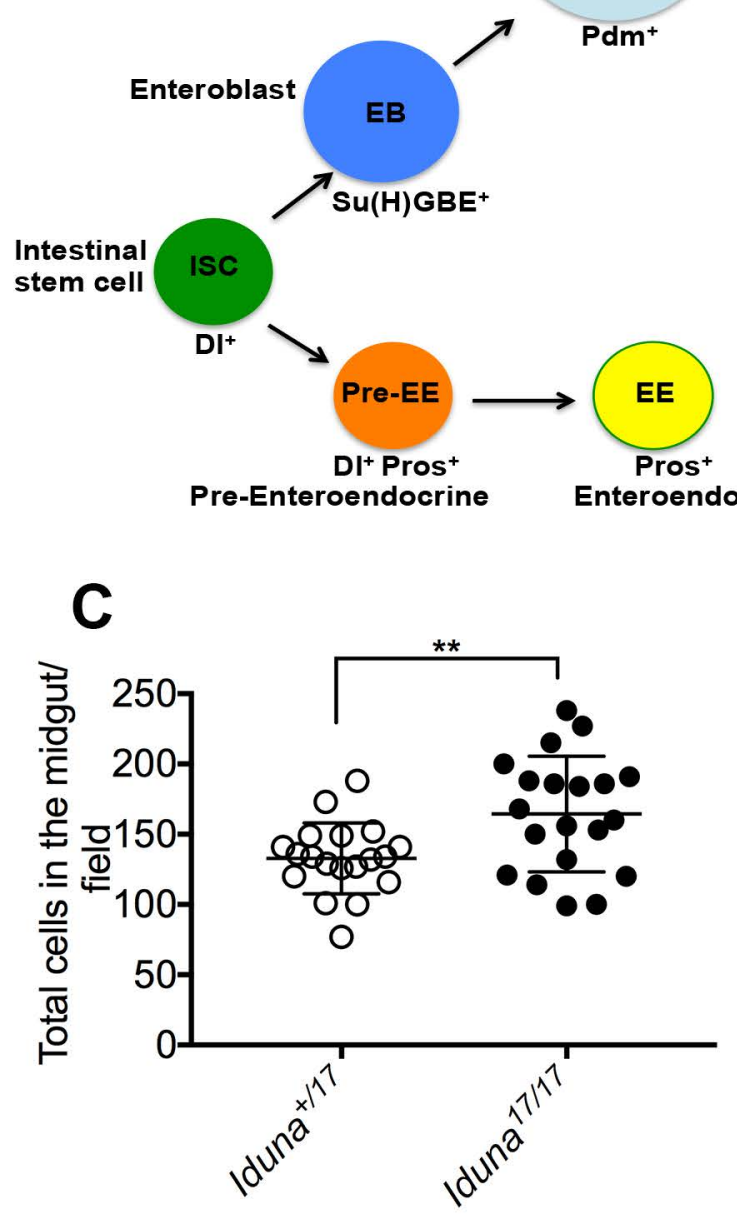

aCC-BY-NC-ND 4.0 Internatio Dro ticesosshila midgut

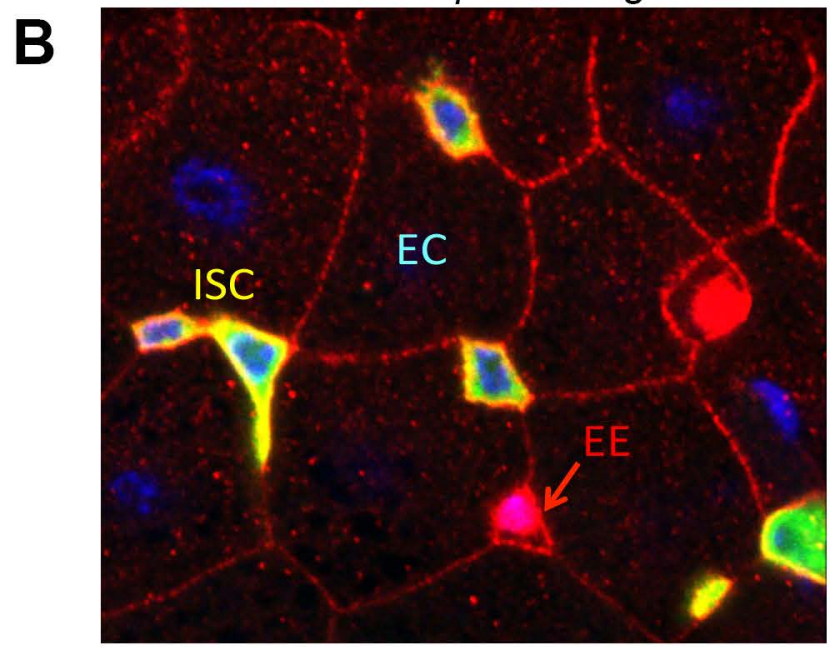

Escargot/Prospero/Armadillo/DAPI

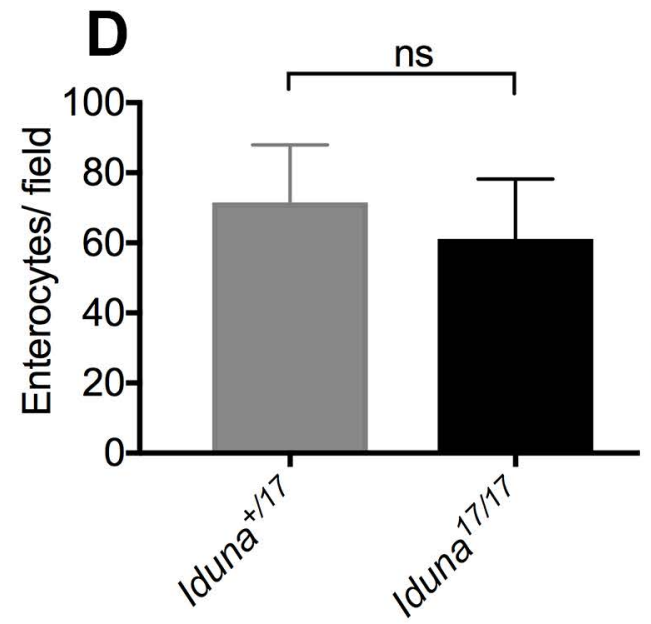

E

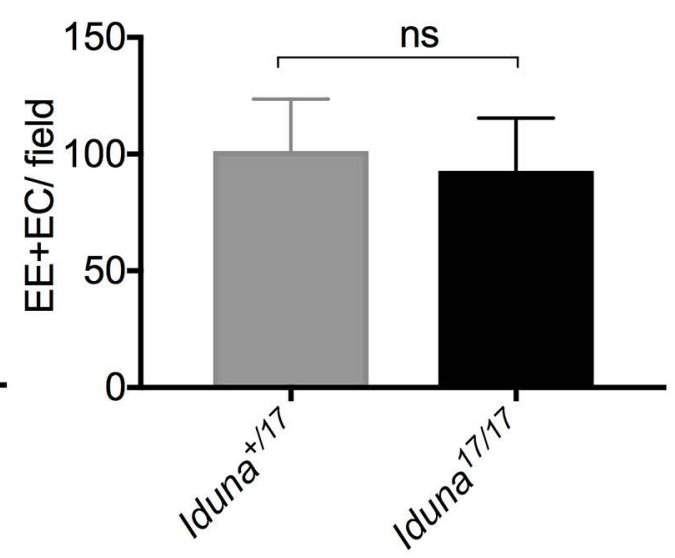

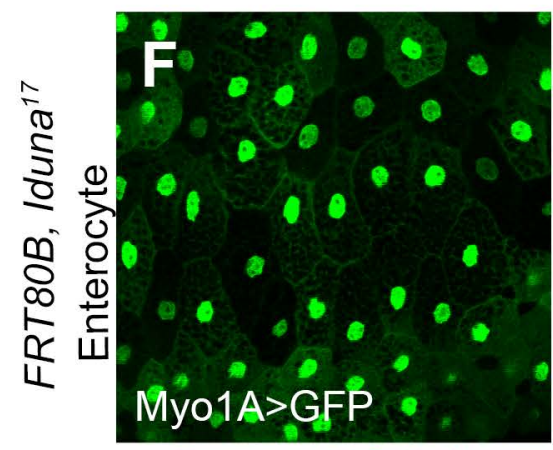

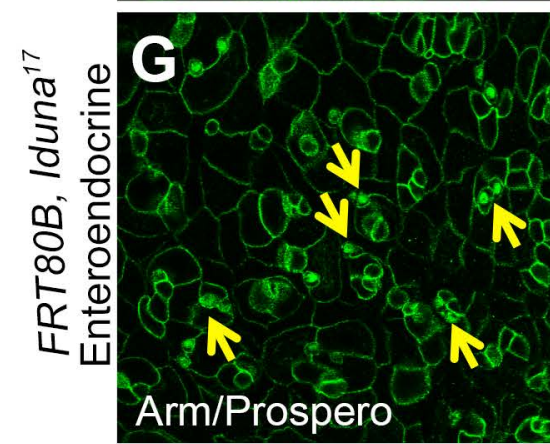

NIs-RFP

DAPI
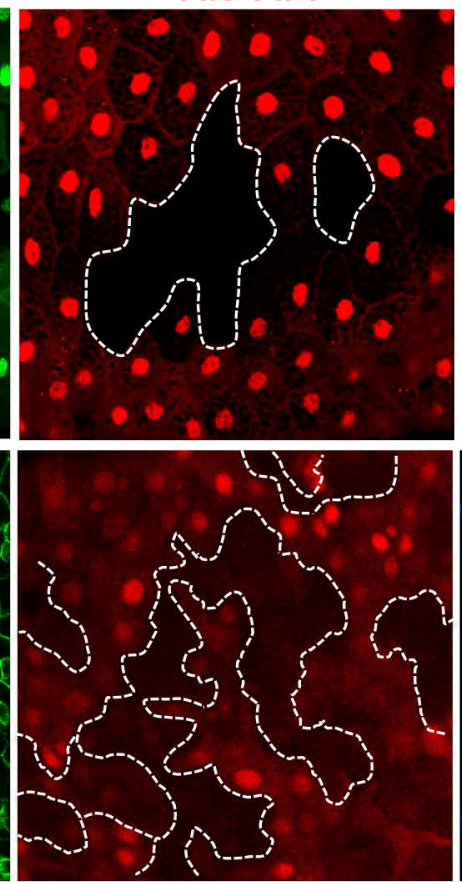

Merged
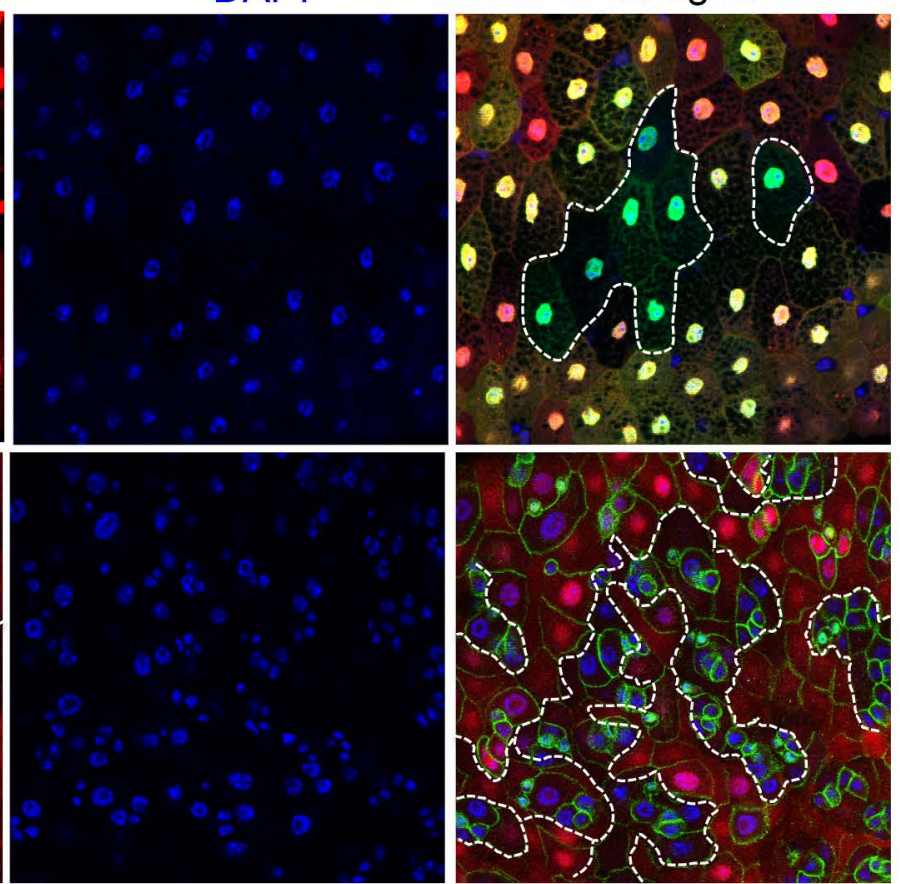
_. bioRxiv preprint doi: https://doi.org/10.1101/296830; this version posted January 15,2019 . The copyright holder for this preprint (which was not FIg Uqe 85 peer review) is the author/funder, who has granted bioRxiv a license to display the preprint in perpetuity. It is made available under

A RNAi-mediated Iduna depletion in enterocytes

B
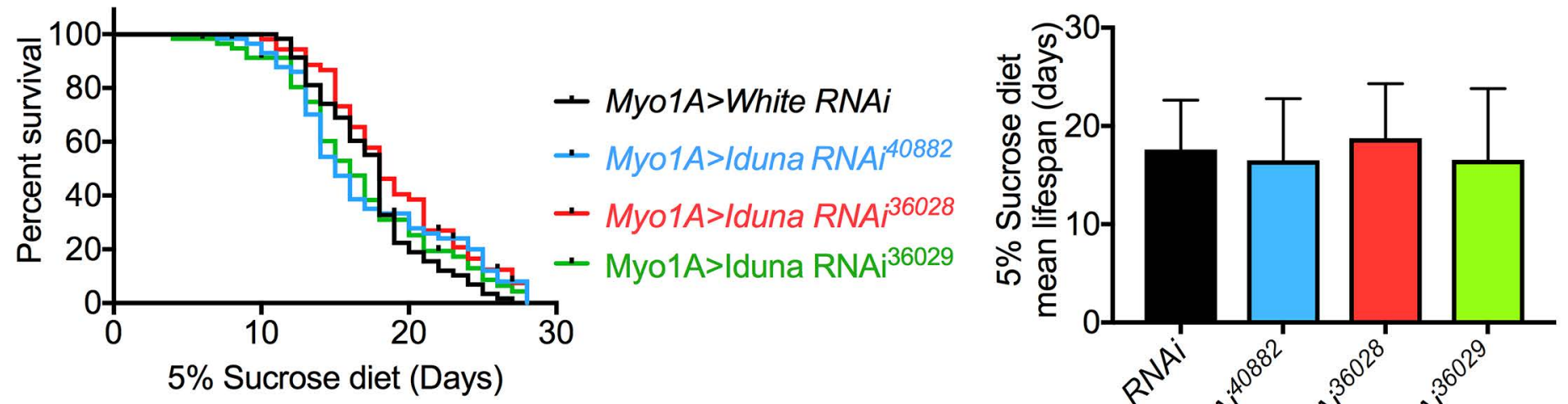

C
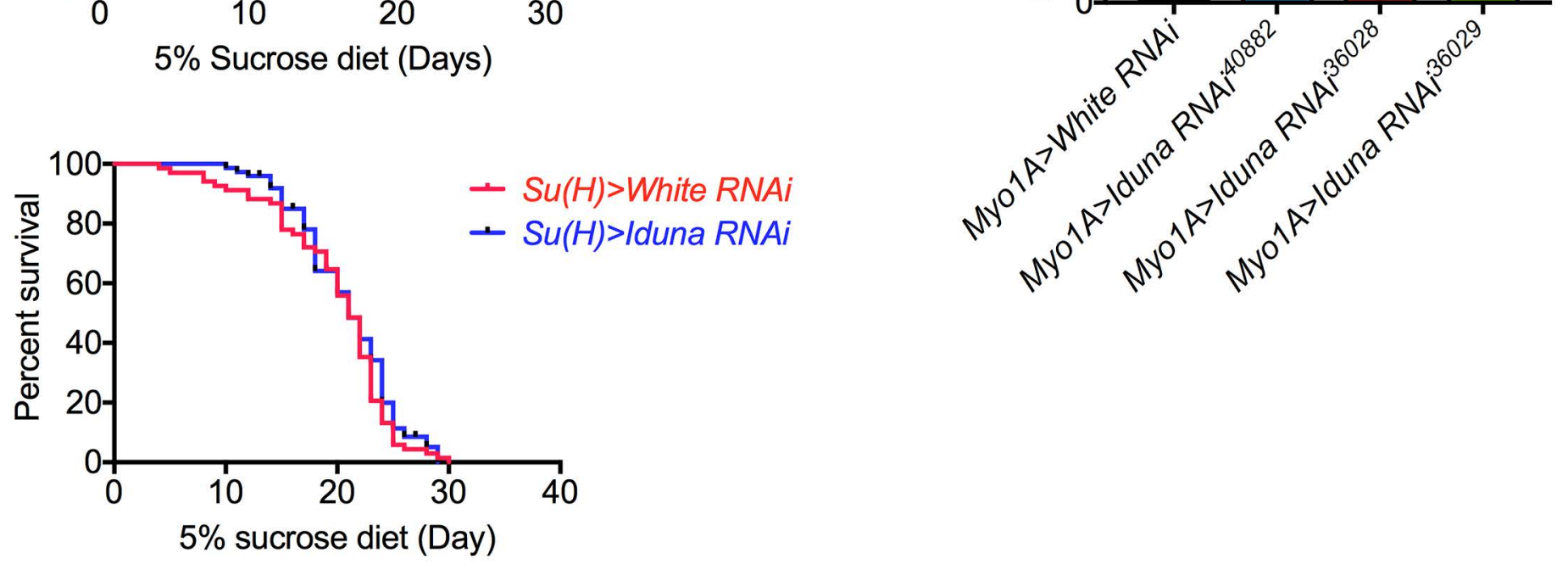

$\mathbf{D}$

Ectopic expression of Iduna in enterocytes

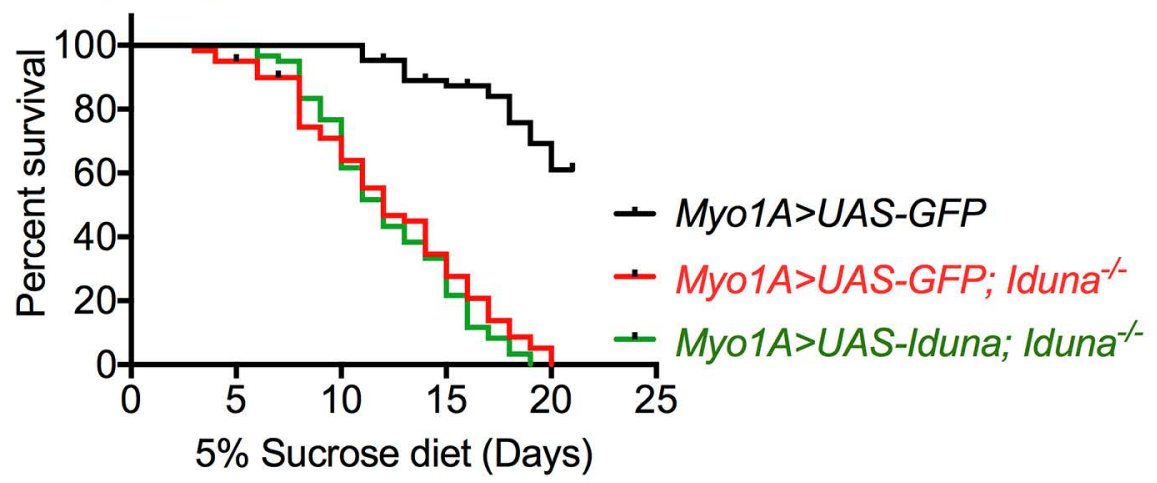

E

$5 \%$ sucrose diet

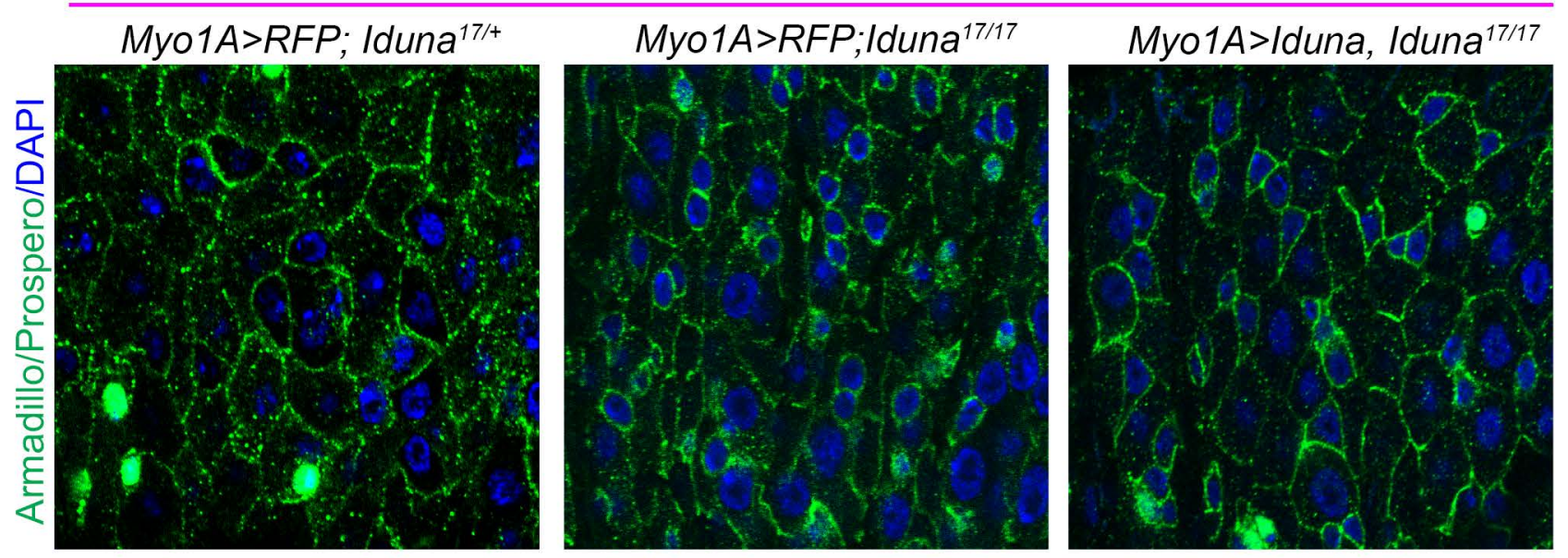


bioRxivaregrint doi: https://doi.org/10.1101/296830; this version posted January 15, 2019. The copyright holder for this preprint (which was not

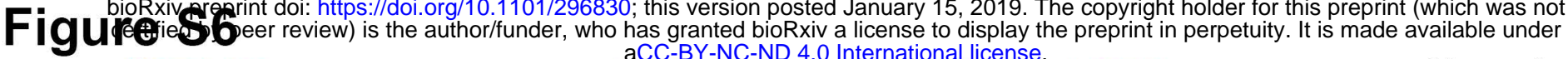

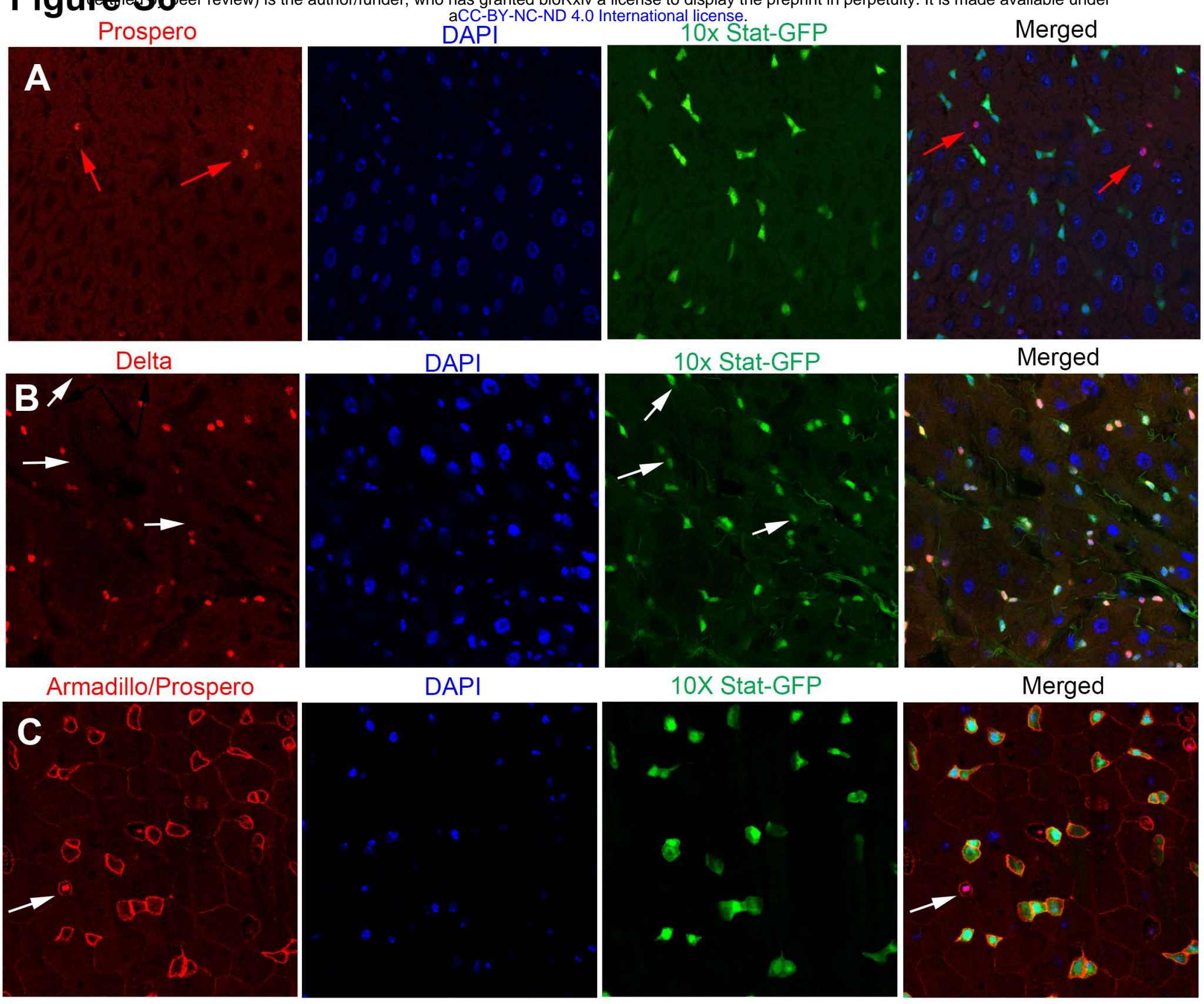


bioRxiv preprint doi: https://doi.org/10.1101/296830; this version posted January 15,2019 . The copyright holder for this preprint (which was not certified by peer review) is the author/funder, who has granted bioRxiv a license to display the preprint in perpetuity. It is made available under Figure S7 aCC-BY-NC-ND 4.0 International license.

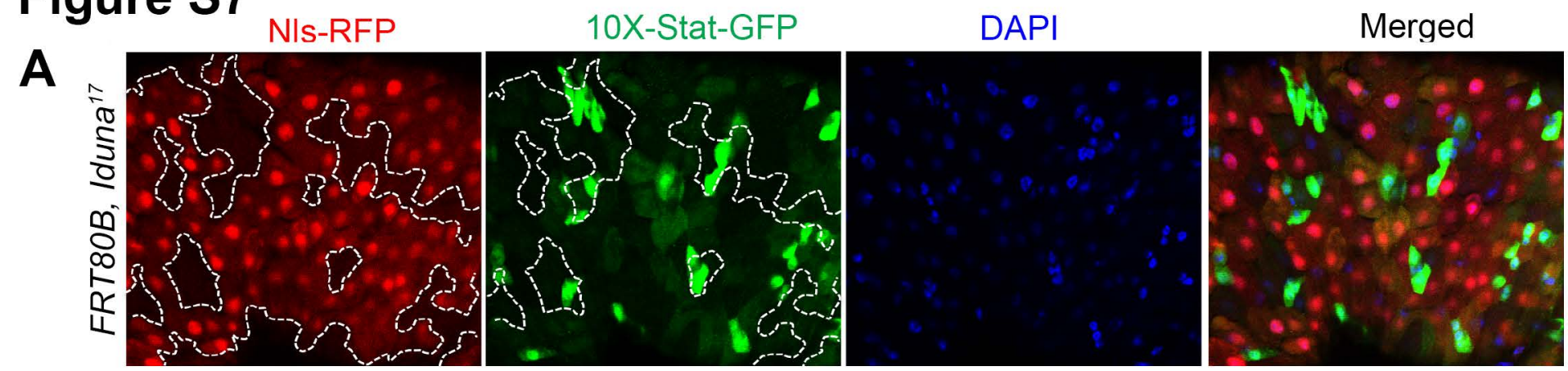

B

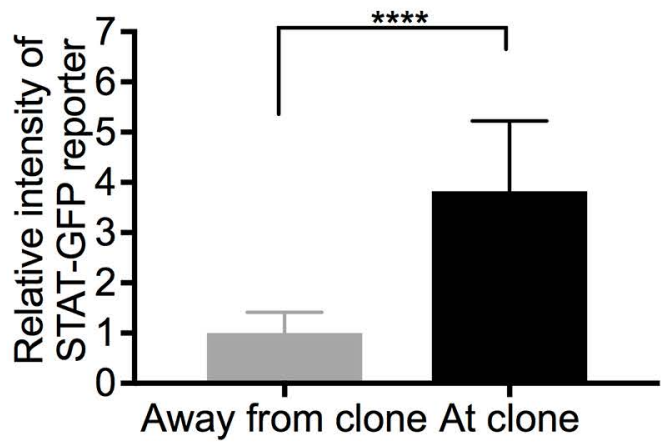

Iduna ${ }^{17 /+}$

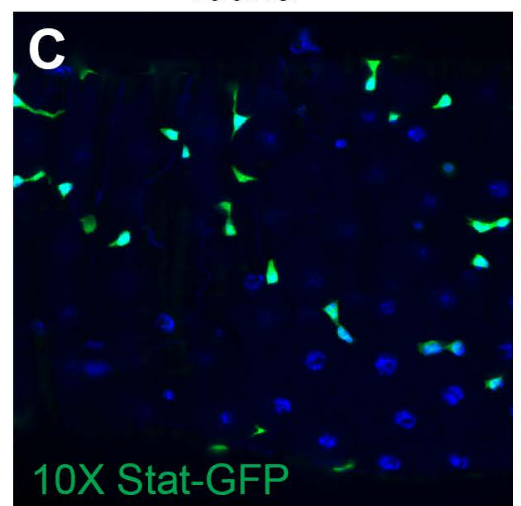

Iduna ${ }^{+/-}$

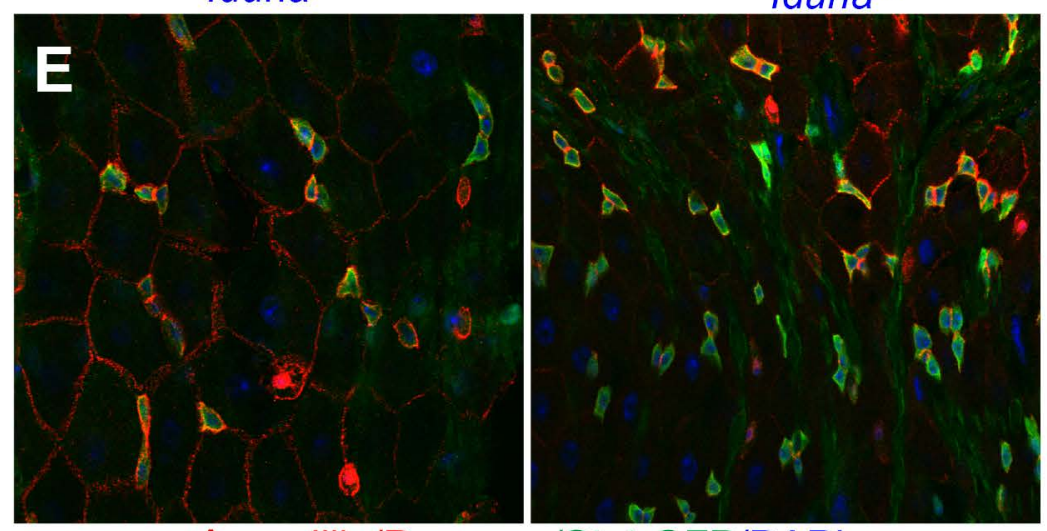

Armadillo/Prospero/Stat-GFP/DAPI
Iduna $a^{17 / 17}$

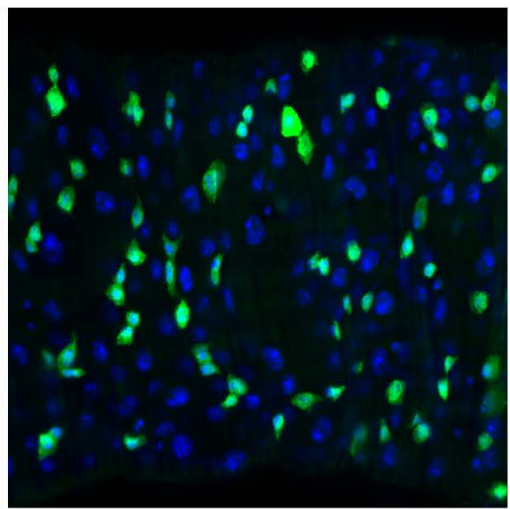

Iduna-s

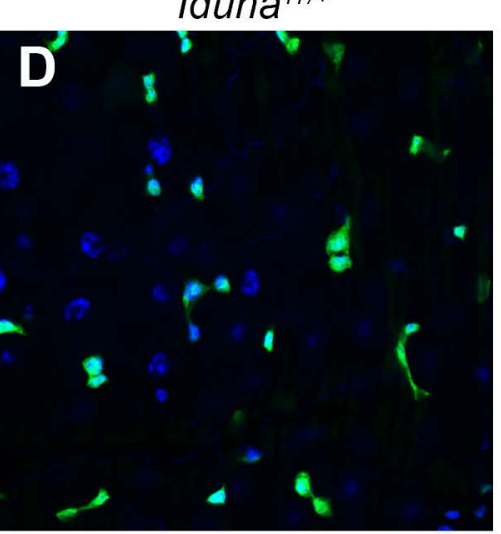

Iduna ${ }^{-/+}$

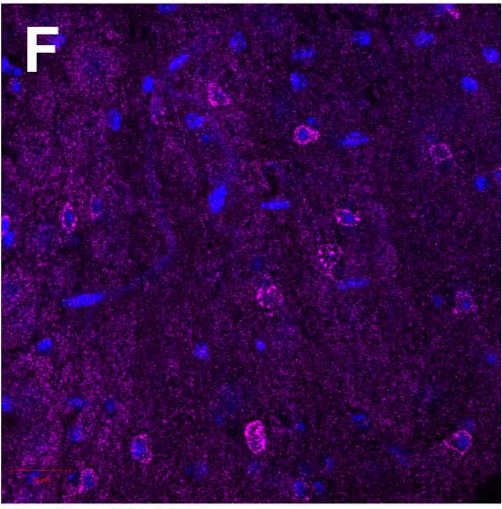

Delta/DAPI

Iduna ${ }^{17 / 17}$

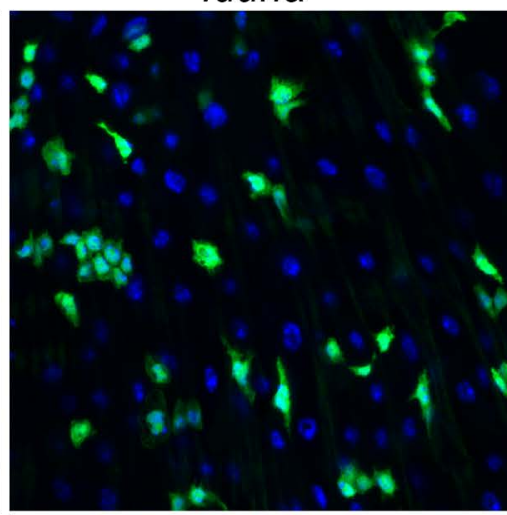

Iduna ${ }^{-/}$

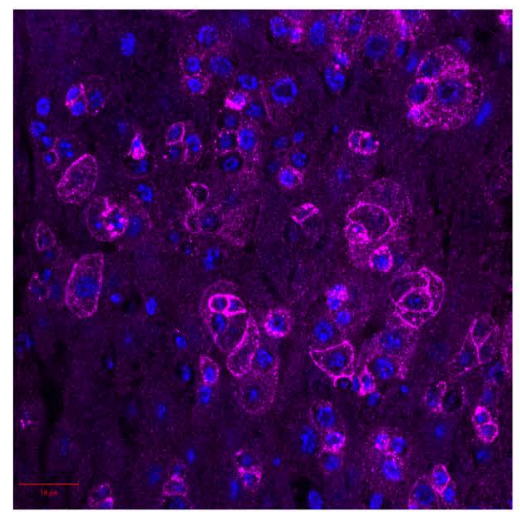


Fio bioRxiv pregrint doi: https://doi.org/10.1101/296830; this version posted January 15,2019 . The copyright holder for this preprint (which was not aCC-BY-NC-ND 4.0 International license.
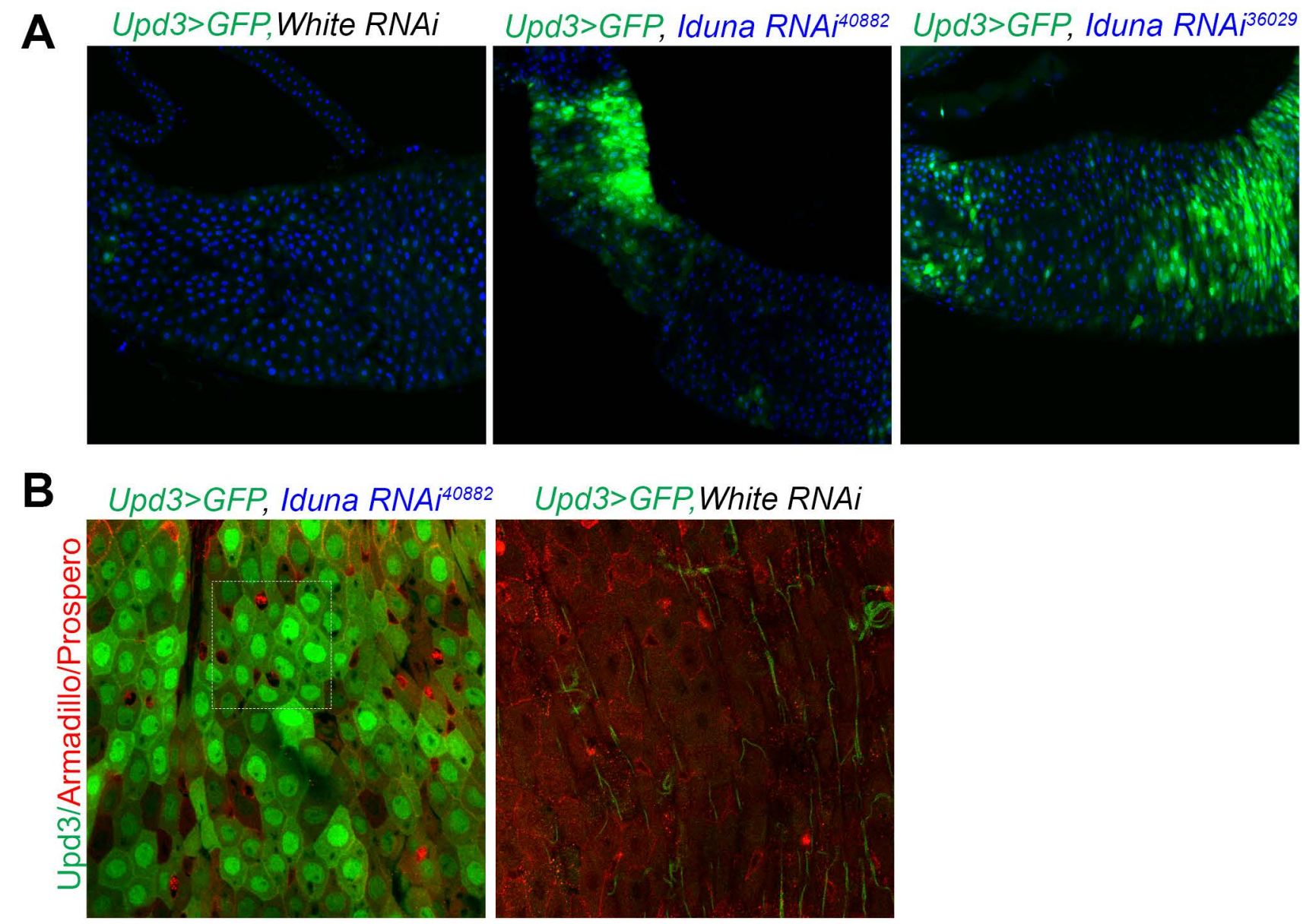

\section{Upd3> GFP, White RNAi}

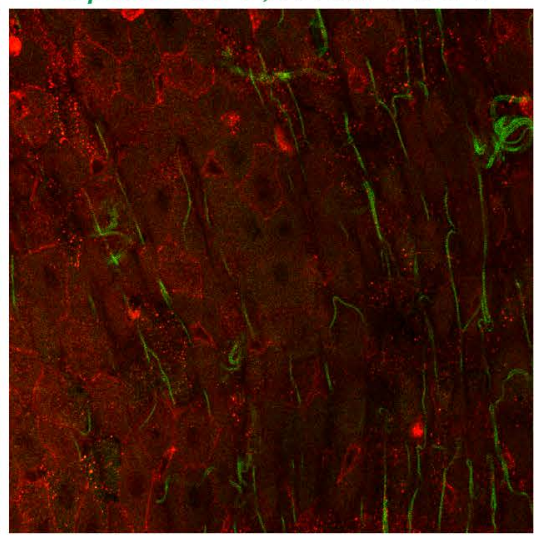

C

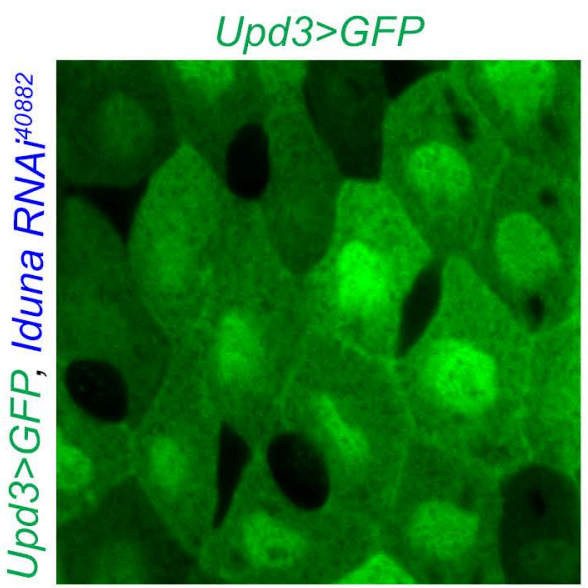

Armadillo/Prospero

Merged
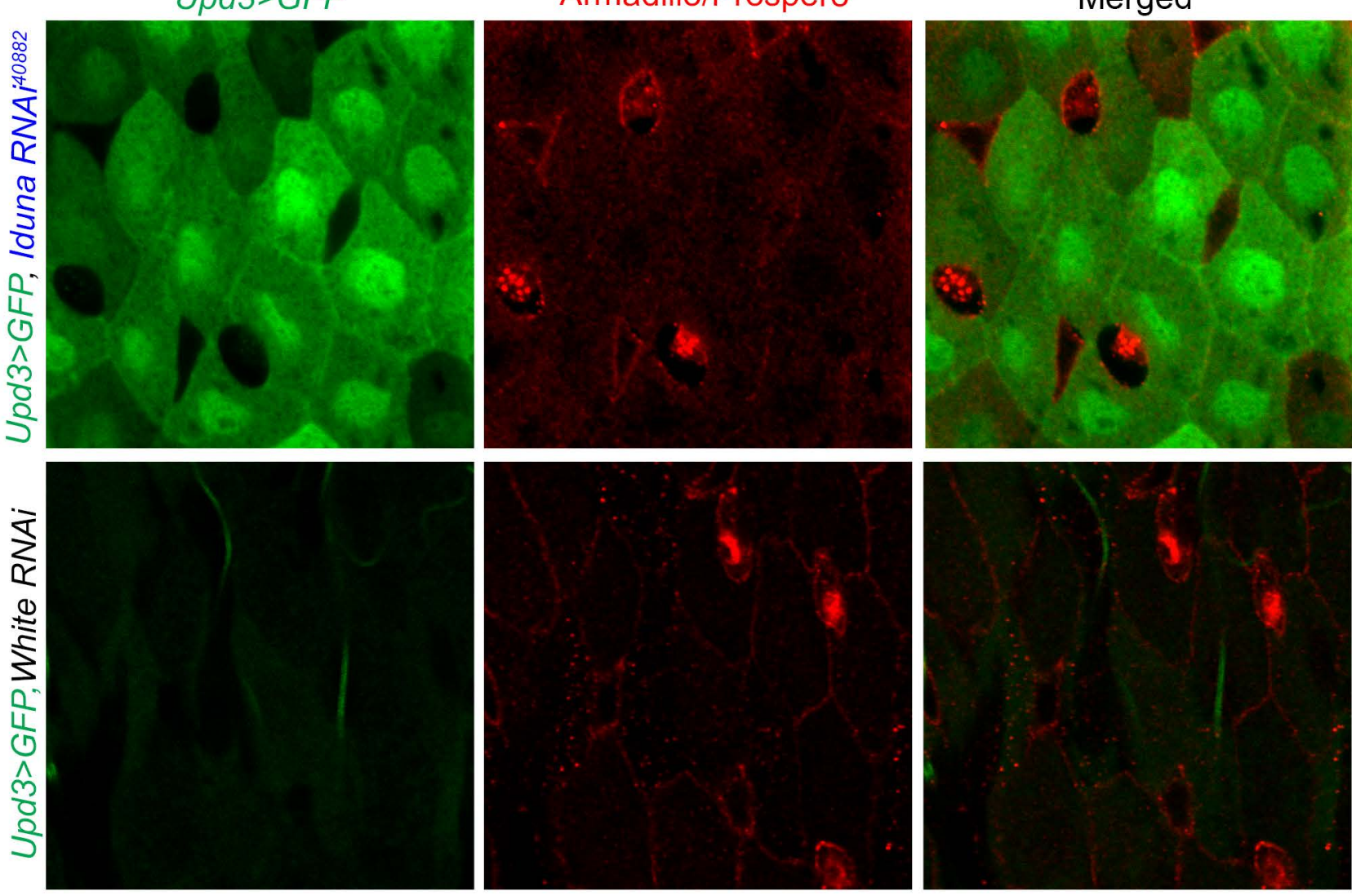